\title{
Synthesis and in vitro evaluation of vanillin derivatives as multi-target therapeutics for the treatment of Alzheimer's disease.
}

\author{
BLAIKIE, L., KAY, G. and KONG THOO LIN, P.
}




\title{
Synthesis and in vitro evaluation of vanillin derivatives as multi-target therapeutics for the treatment of Alzheimer's disease
}

\author{
Laura Blaikie, Graeme Kay, Paul Kong Thoo Lin \\ School of Pharmacy and Life Sciences, Robert Gordon University, Aberdeen, \\ Scotland
}

\begin{abstract}
A number of novel naphthalimido and phthalimido vanillin derivatives were synthesised, and evaluated as antioxidants and cholinesterase inhibitors in vitro. Antioxidant activity was assessed using DPPH, FRAP, and ORAC assays. All compounds demonstrated enhanced activity compared to the parent compound, vanillin. They also exhibited BuChE selectivity in Ellman's assay. A lead compound, $\quad 2 a$ (2-(3-(bis(4-hydroxy-3-methoxybenzyl)amino)propyl)-1Hbenzo[de]isoquinoline-1,3(2H)-dione), was identified and displayed strong antioxidant activity ( $\mathrm{IC}_{50}$ of $16.67 \mu \mathrm{M}$ in the DPPH assay, a 25 -fold increase in activity compared to vanillin in the FRAP assay, and 9.43 TE in the ORAC assay). Furthermore, 2a exhibited potent BuChE selectivity, with an IC $_{50}$ of $0.27 \mu \mathrm{M}$ which was around 53-fold greater than the corresponding AChE inhibitory activity. Molecular modelling studies showed that molecules with bulkier groups, as in $\mathbf{2 a}$, exhibited better BuChE selectivity. This work provides a promising basis for the development of multi-target hybrid compounds based on vanillin as potential $A D$ therapeutics.
\end{abstract}

Keywords: Alzheimer's disease, vanillin derivatives, antioxidant, cholinesterase inhibitor, binding conformation, multi-target strategy

Alzheimer's disease (AD) is a major cause of death worldwide, and its prevalence is expected to rise exponentially with an ageing global population. As the most common neurodegenerative disease, $A D$ has led to an unprecedented social and economic burden.1,2 At present, the exact cause of the disease remains poorly understood although age has been identified as the major risk factor of AD. ${ }^{3}$ With no disease-modifying drugs currently available and clinical trials with one of the highest failure rates in any therapeutic area, ${ }^{4-6}$ the predicted impact of this debilitating disease is increasingly bleak. $A D$ is a complex, multifactorial disease. ${ }^{7}$ Therefore the drugs currently prescribed for $A D$, which act against a single target associated with disease, have a limited efficacy and are capable of reducing symptoms only. ${ }^{5}$ As a result, research has been particularly focused on the development of multi-target drugs since the beginning of the century. ${ }^{8-11}$

Through the extensive research into the origin of $A D$ development, several hallmarks of the disease have been identified. These include cholinesterase 
enzymes, and oxidative stress. ${ }^{12}$ Cholinesterase inhibitors constitute three of the current four clinically available drugs for AD. These are the reversible inhibitors of acetylcholinesterase (AChE): galantamine, rivastigmine, and donepezil. ${ }^{13}$ The cholinergic hypothesis for AD has been widely reported, and attributes the reduced activity of the neurotransmitter acetylcholine (ACh) for the cognitive decline associated with AD cases. ${ }^{14,15}$ Butyrylcholinesterase (BuChE), an isoform of AChE, has gained attention recently for its association with AD development. ${ }^{16-20}$ The activity of the BuChE enzyme has been found to increase as the severity of the disease advances, whereas AChE activity decreases. ${ }^{21}$ Preliminary studies of BuChE inhibitors have reported elevated ACh levels and improved cognition. ${ }^{22-28}$ Notably, BuChE inhibitors also demonstrated non-toxicity at high doses, indicating that treatment with this type of inhibitor will not induce the same adverse gastrointestinal effects as observed with the use of AChE inhibitors. ${ }^{16,24}$ In addition to its association with amyloid plaque formation, increased BuChE activity is related to the development of neurofibrillary tangles and inflammation. ${ }^{29,30}$

Oxidative stress has been associated with the pathological development of $A D$, as well as numerous other diseases including cancer, diabetes, and other neurological disorders. ${ }^{31}$ Oxidative stress occurs as the result of an imbalance in the levels of pro-oxidants and antioxidants in the body, and consequently reactive oxygen species (ROS) and free radicals accumulate. These highly reactive species can cause significant damage to fundamental cellular molecules (including DNA, proteins, and lipids) and generate toxic by-products, eventually resulting in cell death. ${ }^{31,32}$ Oxidative stress has also been linked to the aggregation of amyloid plaques and the deposition of hyperphosphorylated tau. ${ }^{33,34}$

Given the mounting evidence that the cause of $A D$ could be of varied origin, the multi-target approach is becoming a leading strategy for drug development. 35,36 This approach overcomes the challenges associated with the administration of combination therapies, such as compliance issues as well as potentially harmful drug-drug interactions. ${ }^{37}$ Vanillin derivatives as multi-target drugs for the treatment of $A D$ have been reported in recent years, with positive pharmacokinetic and pharmacodynamic findings. Vanillin is a natural compound derived from the vanilla bean (Vanilla planifolia) with strong antioxidant activity in addition to antiinflammatory, anti-mutagenic, anti-metastatic, and anti-depressant properties. ${ }^{38}$ It has also been shown to prevent amyloid aggregation and inhibit AChE activity in vitro and in vivo. ${ }^{39,40}$ Vanillin derivatives have exhibited enhanced antioxidant potential and protective effects against oxidative stress in neuroblastoma cells. ${ }^{41,42}$ Naphthalimide and phthalimide derivatives have also been studied as potential therapeutics for a variety of disorders due to their highly diverse activities against pharmacologically relevant targets. In particular for $A D$, this includes antioxidant, anti-inflammatory, and anti-AChE activity. ${ }^{27,43-46}$ 
In the work presented herein, the design, synthesis, and in vitro evaluation of novel vanillin derivatives is described. Furthermore, in silico simulations are performed on the lead structure to explain its activity and selectivity on the cholinesterase enzymes. While vanillin, naphthalimide and phthalimide derivatives have been explored as AChE-selective inhibitors previously, ${ }^{40,43,45}$ here we demonstrate for the first time the combination of pharmacophores as BuChEselective inhibitors together with their strong antioxidant properties.

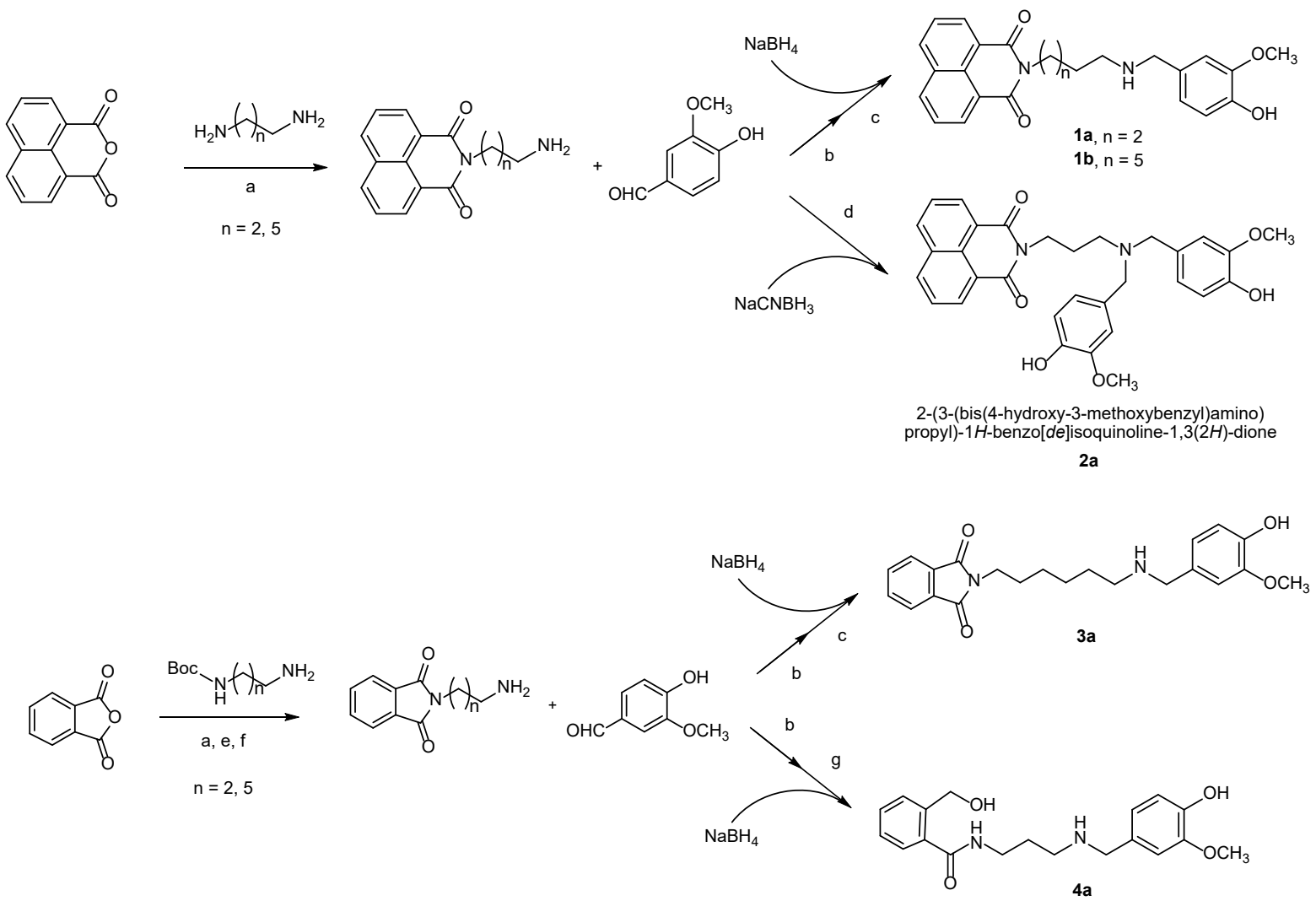

Scheme 1 Synthesis of vanillin derivatives $(\mathbf{1} \mathbf{a}-\mathbf{4 a})$. Reagents and conditions: a) excess diamine, where $n=2(\mathbf{1 a}, \mathbf{2 a}, \mathbf{4 a})$ or $5(\mathbf{1} \mathbf{b}, \mathbf{3 a})$, ethanol, reflux, 1 hour; b) excess vanillin, methanol, RT, 24 hours; c) $\mathrm{NaBH}_{4}$, methanol, RT, 4 hours; d) excess vanillin, $\mathrm{NaCNBH}_{3}, \mathrm{ZnCl}_{2}$ methanol, reflux, 24 hours; e) $\mathrm{HCl}$, dioxane, RT, 2 hours; f) triethylamine, methanol, RT, 2 hours; g) $\mathrm{NaBH}_{4}$, methanol, reflux, 4 hours.

The synthesis of mono-vanillin derivatives combined with naphthalimide $(\mathbf{1 a}, \mathbf{1} \mathbf{b})$, a di-vanillin derivative with naphthalimide (2a), and mono-vanillin derivatives with phthalimide as a closed (3a) or open ring (4a) are shown in Scheme 1. All compounds were fully characterised by ${ }^{1} \mathrm{H}-\mathrm{NMR},{ }^{13} \mathrm{C}-\mathrm{NMR}$, and mass spectrometry (see Supplementary Information). The novel compounds were then subjected to a series of in vitro assays to evaluate their antioxidant activity; including DPPH, FRAP, and ORAC. Furthermore, the inhibitory activity of the compounds against AChE and BuChE was determined using the method of Ellman ${ }^{47}$ with minor 
modifications. Using molecular modelling, the binding conformations of the novel compounds within the active sites of both cholinesterase isoforms was studied. In silico analyses were performed using PyRx (Autodock Vina 1.1.2) ${ }^{48}$ and PyMol (PyMol Molecular Graphics System, version 2.3.3, Schrodinger, LLC) software to provide an explanation for the enhanced activity of the compound $\mathbf{2 a}$. The logP and BBB (blood brain barrier) permeation predictions were also performed for $\mathbf{2 a}$ using ChemDraw Professional 16.0 software and the BBB prediction server generated by Liu et al. ${ }^{49}$ (https://www.cbligand.org/BBB/) respectively.

Aminonaphthalimide intermediates (Scheme 1 ) were formed using the method of Noro et al. ${ }^{50}$ Mono-vanillin derivatives $(\mathbf{1 a}, \mathbf{1} \mathbf{b}, \mathbf{3 a}, \mathbf{4 a})$ were synthesised in a stepwise manner, with initial condensation of vanillin to form the imine and subsequent reduction by sodium borohydride to the corresponding secondary amine. ${ }^{42}$ For the synthesis of the di-vanillin derivative, $\mathbf{2} \mathbf{a}$, the reducing agent sodium cyanoborohydride was employed in a one-step reductive amination reaction. As for $\mathbf{3 a}$ and $\mathbf{4 a}$, a Boc-protected diamine was used to avoid aminolysis of the phthalimido ring. The Boc group was removed with $\mathrm{HCl}$ in dioxane to yield the hydrochloride salt. The free amine was released with excess triethylamine for subsequent reaction. Interestingly, when reduction was carried out with sodium borohydride at RT, 3a was formed. However, under refluxing conditions, further reduction occurred as in $\mathbf{4 a}$. In this case, the phthalimido group underwent ring opening to the corresponding alcohol. Reduction of the phthalimido ring with sodium borohydride has been reported previously, with the initial formation of hydroxyphthalimidine on reduction of the phthalimido carbonyl group followed by the formation of the corresponding hydroxymethylbenzamide in conjunction with the opening of the phthalimido ring (Scheme 2). ${ }^{51}$

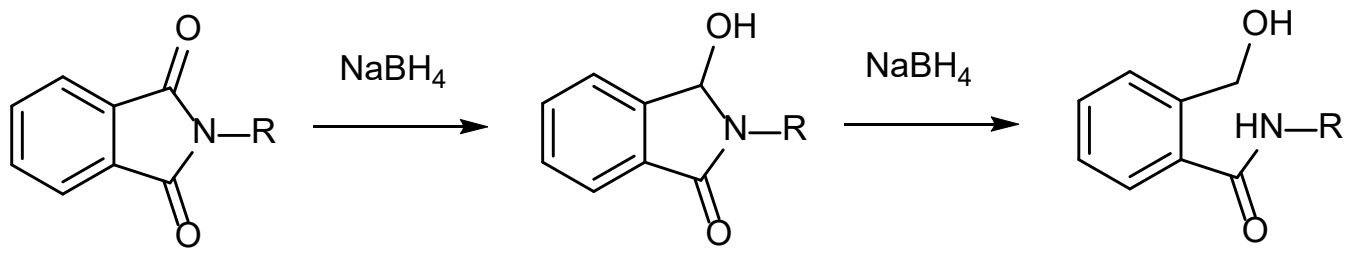

Scheme 2 Reduction and subsequent hydrolysis of the phthalimido group by sodium borohydride, as observed in the synthesis of compound $\mathbf{4 a}$.

This highlights the poor stability of the phthalimido group, particularly in comparison to naphthalimide which remained unaffected when subjected to similar conditions. Compounds $\mathbf{2 a}, \mathbf{3 a}$, and $\mathbf{4 a}$ were subjected to column chromatography with chloroform/methanol as the eluent, while 1a and 1 $\mathbf{b}$ were recrystallised from ethanol (6-82\% yields). 
The antioxidant activity of all the compounds was evaluated using DPPH, FRAP, and ORAC assays using the methods of Payet et al. ${ }^{52}$, Firuzi et al. ${ }^{53}$, and Huang et al. ${ }^{54}$ respectively. All assays were carried out in a 96-well plate, however a blackwalled plate was used for the ORAC assay. Stock solutions (10 mM) of the compounds were prepared in DMSO, then dilutions were made using the appropriate solvent. In each case, it was ensured that the concentration of DMSO in the wells was no greater than $1 \%$, and a control with the highest concentration of DMSO was always included. The DPPH assay was employed to assess the capacity of the compounds to scavenge DPPH free radicals, while the FRAP assay tested their reducing power toward ferric ions, and the ORAC assay was used to evaluate their ability to prevent oxidative degradation of fluorescein. The results from each assay are illustrated in Table 1.

Table 1 In vitro antioxidant activity of vanillin derivatives in DPPH, FRAP, and ORAC assays.

\begin{tabular}{llll}
\hline Compound & DPPH IC $_{50}(\mu \mathrm{M})^{\mathrm{a}}$ & FRAP $(\mathrm{TE})^{\mathrm{b}}$ & ORAC $(\mathrm{TE})^{\mathrm{b}}$ \\
\hline $\mathbf{1 a}$ & $62.00 \pm 5.06$ & $0.26 \pm 0.02$ & $8.10 \pm 0.34$ \\
$\mathbf{1 b}$ & $70.00 \pm 2.64$ & $0.34 \pm 0.01$ & $6.70 \pm 1.08$ \\
$\mathbf{2 a}$ & $16.67 \pm 1.52$ & $0.49 \pm 0.02$ & $9.43 \pm 0.86$ \\
$\mathbf{3 a}$ & $82.33 \pm 3.05$ & $0.23 \pm 0.01$ & $13.23 \pm 0.98$ \\
$\mathbf{4 a}$ & $112.80 \pm 1.93$ & $0.96 \pm 0.06$ & $\mathrm{NT}^{\mathrm{c}}$ \\
Vanillin & $7915.00 \pm 24.00$ & $0.02 \pm 0.01$ & $2.20 \pm 0.30$
\end{tabular}

${ }^{a} \mathrm{IC}_{50}$ is the concentration at which $50 \%$ of DPPH radicals were scavenged (mean values are reported with standard deviation \pm values of 3 independent experiments).

b TE is calculated by comparison of the slopes of the calibration curves obtained for Trolox and for each compound (mean values are reported with standard deviation \pm values of 3 independent experiments).

${ }^{\mathrm{c}} \mathrm{NT}=$ Not tested.

All tested compounds exhibited strong and enhanced antioxidant activity when compared to vanillin. In general, compound $\mathbf{2 a}$ exhibited the strongest antioxidant activity. This may be due to its additional vanillin moiety, which provided further antioxidant power. ${ }^{41}$ The mono-vanillin naphthalimido derivatives $(\mathbf{1} \mathbf{a}, \mathbf{1} \mathbf{b})$ delivered similar activities in each assay. Although chain length was not expected to affect antioxidant activity, ${ }^{41}$ the hexyl derivatives exhibited the strongest antioxidant activity in the ORAC assay. In particular, 3a demonstrated the greatest activity in the ORAC assay yet showed less activity in the other assays. It is possible that $\mathbf{3 a}$ acts as an antioxidant via an alternative route to the naphthalimido compounds. Similarly, the other phthalimido-based 
compound $\mathbf{4 a}$ with an open ring exhibited the strongest FRAP activity with an increase of around 2-fold the activity of $\mathbf{2 a}$. This enhanced activity is likely as a result of the additional alcohol group in the open phthalimido ring. However, in the DPPH assay, $\mathbf{4 a}$ exhibited the least activity with an $\mathrm{IC}_{50}$ value 7 -fold higher than $\mathbf{2 a}$. The striking results of $\mathbf{3 a}$ and $\mathbf{4 a}$ demonstrate that the vanillin moiety may not be solely responsible for the antioxidant activity of the compounds in this work, and that the phthalimido derivatives likely act as antioxidants via an alternative route to the naphthalimido derivatives. Overall, it is evident that the di-vanillin derivative $\mathbf{2} \mathbf{a}$ is the most active antioxidant from this series of compounds.

The effect of the compounds on ChE activity was evaluated using Ellman's assay as previously described with minor changes. ${ }^{47}$ Stock solutions of the compounds were prepared in DMSO, and diluted to the desired concentration with maximum $1 \%$ DMSO content. The compounds were screened against electric eel AChE, and equine BuChE. A control with the highest concentration of DMSO was included. The results from the assays are presented in Table 2.

Table 2 In vitro inhibitory activity of vanillin derivatives in Ellman's assay against AChE and BuChE.

\begin{tabular}{llll}
\hline Compound & AChE IC $_{50}(\mu \mathrm{M})^{\mathrm{a}}$ & BuChE IC $_{50}(\mu \mathrm{M})^{\mathrm{a}}$ & $\mathrm{SI}^{\mathrm{b}}$ \\
\hline $\mathbf{1 a}$ & $13.67 \pm 1.52$ & $0.90 \pm 0.21$ & 15.19 \\
$\mathbf{1 b}$ & $3.33 \pm 0.57$ & $1.50 \pm 0.26$ & 2.22 \\
$\mathbf{2 a}$ & $14.33 \pm 1.52$ & $0.27 \pm 0.03$ & 53.07 \\
$\mathbf{3 a}$ & $4.67 \pm 0.57$ & $0.37 \pm 0.05$ & 12.62 \\
$\mathbf{4 a}$ & $\mathrm{NT}^{\mathrm{c}}$ & $\mathrm{NT}^{\mathrm{c}}$ & - \\
Neostigmine & $7.50 \pm 0.70$ & $2.93 \pm 0.20$ & 2.56 \\
\hline a IC & is is the concentration at which 50\% of the enzyme activity was inhibited \\
(mean values are reported with standard deviation \pm values of 3 independent \\
experiments). \\
b SI: selectivity index (AChE IC $50 /$ BuChE IC 50$).$ \\
c NT = Not tested.
\end{tabular}

All compounds demonstrated between 2-53 times selectivity for BuChE over AChE, as illustrated by the selectivity index. In general, the selectivity for BuChE over AChE increased as the size of the molecule increased. Compound $\mathbf{2 a}$ had the highest selectivity index, and also has the highest molecular weight of all the tested compounds $(526 \mathrm{~g} / \mathrm{mol})$. Further, the control neostigmine has the lowest molecular weight at $223 \mathrm{~g} / \mathrm{mol}$, and one of the lowest selectivity index values. 
Given that the active site of BuChE is around $200 \AA^{3}$ larger than that of $A C h E$, it is possible that larger compounds are therefore more active against BuChE compared to AChE as the structures are more compatible with the BuChE enzyme active site. However, compound $\mathbf{1 b}$ did not follow this trend. As a result of the flexibility of its long, saturated hexyl chain, it is possible that the conformation that the molecule adopts when binding to the BuChE active site is not optimal for allowing the most interactions with the active site residues. ${ }^{55}$ Nevertheless, it is evident that the flexible hexyl group in $\mathbf{1 b}$ and $\mathbf{3 a}$ is crucial for their enhanced inhibitory activity against AChE. It would appear that the presence of a shorter chain prevents total access of the pharmacophores to bind to the AChE enzyme active site. ${ }^{55}$ Although $\mathbf{3 a}$ exhibited strong activity against both ChE enzymes, the hypothesis reported by Gao et al. ${ }^{43}$ that compounds with bulkier groups exhibit enhanced activity appears to be supported by the results here; for example the authors demonstrated that naphthalimide exhibited enhanced binding compared to phthalimide. While $\mathbf{3 a}$ contains a phthalimido group, compound $\mathbf{1 b}$ with the identical structure aside from a naphthalimido moiety exhibited stronger AChE inhibition ( $\mathrm{IC}_{50}$ values of $4.67 \mu \mathrm{M}$ and $3.33 \mu \mathrm{M}$ respectively). Furthermore, compound $\mathbf{2 a}$ demonstrated the strongest BuChE inhibition which was 1.4-fold higher than $\mathbf{3 a}$ due to its bulky structure involving a naphthalimido group and dual vanillin moieties. However, as highlighted above, the size of the molecule does not appear to be the sole factor affecting the ChE inhibitory activity.

Vanillin alone was found to be inactive against both ChE enzymes within the tested concentration range, therefore the hybridisation of these pharmacophores has contributed to the enhanced multi-target activity. Furthermore, Dinghe et al. ${ }^{56}$ reported that rivastigmine inhibits $\mathrm{BuChE}$ with an $\mathrm{IC}_{50}$ of $0.803 \mu \mathrm{M}$, rendering compound $\mathbf{2 a}$ around 3 -fold more active than a clinically prescribed ChE inhibitor. Despite the lack of approved BuChE-selective inhibitors available on the market, a number of studies have reported strong BuChE inhibitors; including Sawatzky et al. ${ }^{27}$ with carbamate derivatives including a naphthyl compound which demonstrated an $\mathrm{IC}_{50}$ of $2.8 \mu \mathrm{M}$ against BuChE, and Kumar et al. ${ }^{26}$ with phenylbenzofuran derivatives which exhibited an optimum BuChE selectivity index of 28.0. Based on these promising results, the compounds in this work also have strong potential as potent and selective BuChE inhibitors.

To aid in explaining the apparent BuChE selectivity of compound $\mathbf{2 a}$ in addition to its enhanced in vitro enzymatic inhibitory activity compared to neostigmine, molecular modelling studies were performed using ChE human isoform crystal structures. All compounds in this work exhibited stronger binding affinities to the ChE enzymes compared to the known inhibitor, neostigmine (see Supplementary Information). The isoforms share around $50 \%$ of the same amino acids in their structure. However, within their active sites, many of the aromatic amino acids in AChE are replaced with aliphatic amino acids in the BuChE structure. ${ }^{56}$ While 
the depth of the active site gorge is around $20 \AA$ in both cases, ${ }^{29}$ the actual volume of the gorge differs by around $200 \AA^{3}$ with the larger isoform being BuChE. In combination, these structural differences allow the binding of bulkier ligands within the active site of BuChE. ${ }^{16}$ Within the gorge, AChE and BuChE have corresponding binding sites; specifically, the peripheral anionic site (PAS) at the entrance to the gorge, the catalytic triad at the base of the gorge, the catalytic anionic site (CAS), the acyl pocket, and the oxyanion hole which is also located at the base of the active site (Figure 1 ). ${ }^{24}$

Compound $\mathbf{2 a}$ was visualised as a ligand docked in the active sites of both AChE and BuChE to compare its binding properties (Figure 1). As expected, the larger gorge of BuChE allows the entire molecule $\mathbf{2 a}$ to enter the active site and therefore interact with a greater number of key residues. Additional interactions result in stronger binding, ${ }^{43}$ and thus accounts for the enhanced inhibitory activity observed for BuChE in comparison to AChE. As seen in Figure 1, only the naphthalimido moiety is able to enter the active site of AChE, while the vanillin groups are limited to interact with residues around the entrance to the enzyme active site. 

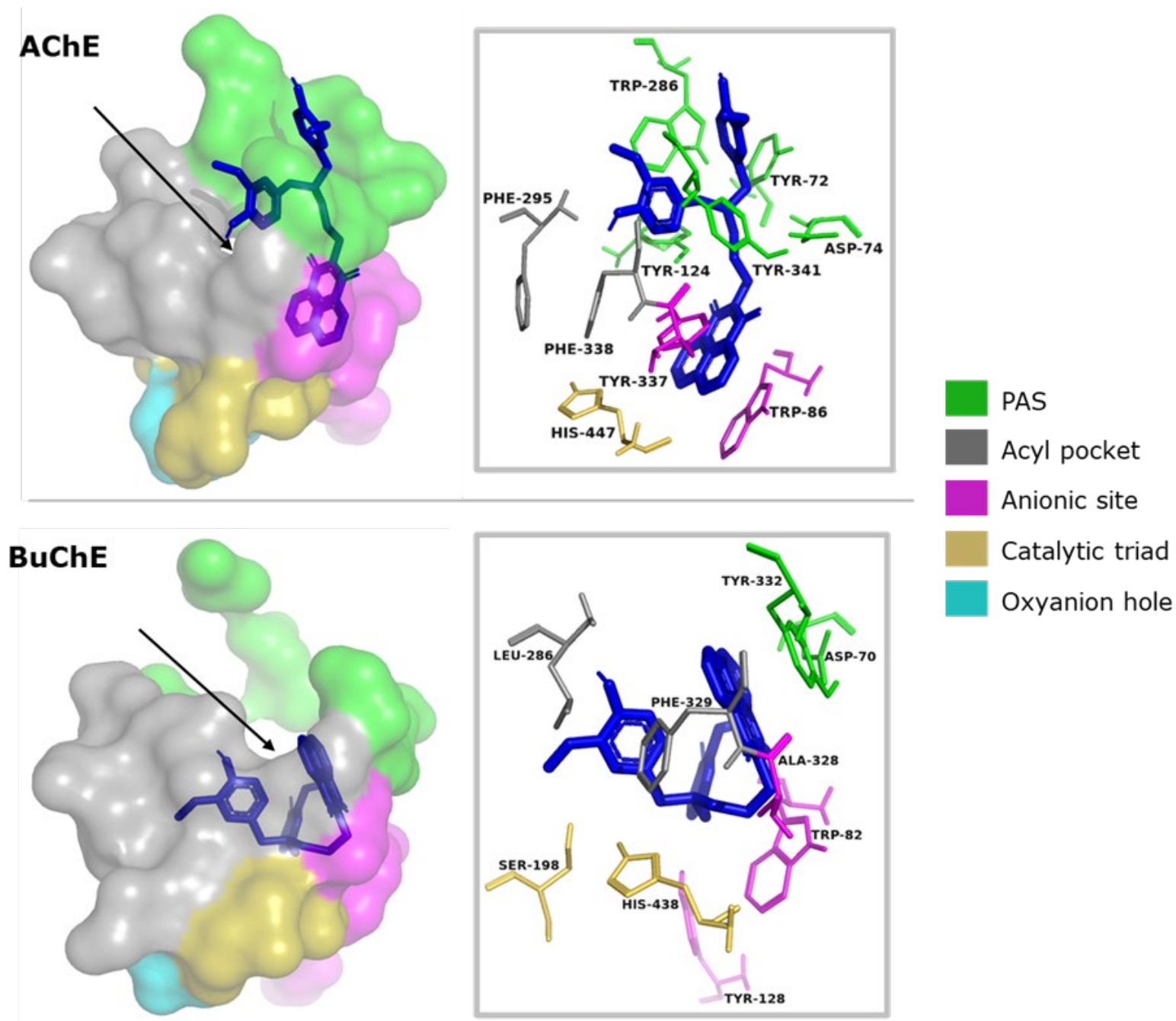

Oxyanion hole

Figure 1 Compound $\mathbf{2 a}$ (blue sticks) docked in AChE and BuChE active sites. The active site gorges on the left are depicted as semi-transparent molecular surfaces with each binding site highlighted. On the right, the key residues involved in the binding of 2a with AChE and BuChE are labelled and highlighted based on each binding site. The peripheral anionic site (PAS) at the rim of the gorge is presented in green. The acyl pocket is depicted in grey and the catalytic anionic site in magenta. The catalytic triad and oxyanion hole at the base of the gorges are gold and cyan respectively. The black arrow indicates the route taken by the ligand to enter the gorge.

To investigate the interactions between the ligand and the ChE enzymes, the hydrogen and hydrophobic interactions were visualised. Within AChE, 2a exhibited hydrogen bonding connecting Tyr 124 (PAS) with a naphthalimido carbonyl, Phe 295 (acyl pocket) with the vanillin hydroxyl group, and Tyr 341 (PAS) with the other naphthalimido carbonyl. The PAS of the AChE enzyme has been associated with the aggregation of amyloid peptides into fibrils, therefore this binding conformation could also reduce ChE-induced aberrant $A \beta$ misfolding. ${ }^{43}$ The naphthalimido group also formed $\pi-\pi$ bonding with Trp 86 (CAS). The short alkyl chain only interacted with the PAS, while the two vanillin groups positioned at the entrance to the gorge formed hydrophobic bonding with the PAS and to the 
acyl pocket to a lesser extent. The binding affinity of neostigmine in AChE was calculated to be $-7.0 \mathrm{kcal} / \mathrm{mol}$ using PyRx. Compound $\mathbf{2 a}$ was found to have a stronger binding affinity for AChE at $-11.3 \mathrm{kcal} / \mathrm{mol}$, which reflects the in vitro results where $\mathbf{2 a}$ demonstrated greater inhibitory activity. Due to the compact structure of neostigmine (Figure 2), it was able to fully enter the AChE active site to form hydrophobic interactions with each of the binding sites (Asp 74, Tyr 341, Tyr 124 in the PAS; Phe 297, Phe 338 in the acyl pocket; Trp 86, Tyr 337 in the CAS; Ser 203 and His 447 in the catalytic triad). However, neostigmine did not form any hydrogen or $\pi-\pi$ bonding with AChE. Overall, it is apparent that a longer chain (i.e. the saturated hexyl chains of compounds $\mathbf{1} \mathbf{b}$ and $\mathbf{3} \mathbf{a}$ ) is beneficial to AChE inhibition as it can allow the formation of extensive hydrophobic interactions with the binding sites located within AChE and reach further within the enzymatic gorge. ${ }^{55}$

AChE

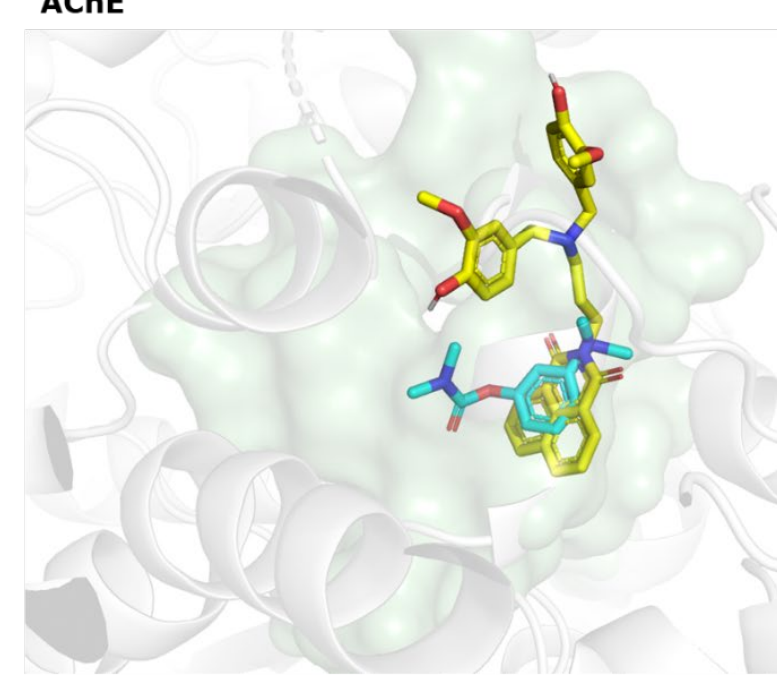

BuChE

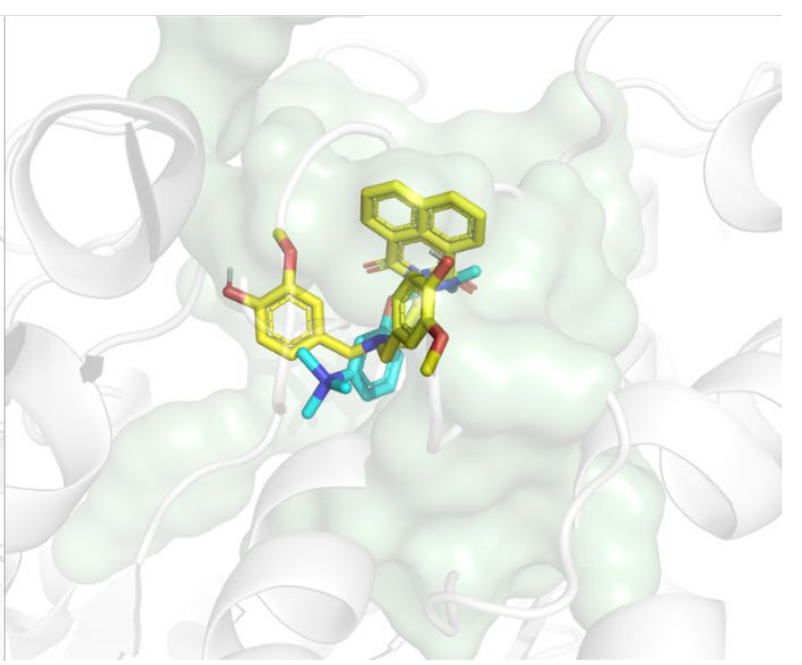

Figure 2 Neostigmine (cyan) and compound 2a (yellow) docked in AChE and BuChE (enzymes depicted in semi-transparent grey), with the active site gorges of each isoform highlighted as semi-transparent green molecular surfaces.

Upon investigating the binding interactions of compound $\mathbf{2 a}$ with BuChE, it forms only one hydrogen bond between Ala 328 (CAS) and the naphthalimido carbonyl. With regards to hydrophobic interactions, $\mathbf{2 a}$ exhibited $\pi-\pi$ bonding between the naphthalimido group and Tyr 332 (PAS). Each vanillin moiety also formed extensive hydrophobic bonding with the acyl pocket, CAS, and catalytic triad. Therefore, it is likely that the additional vanillin group on compound $\mathbf{2 a}$ is responsible for the 3-fold enhanced BuChE inhibitory activity compared to $\mathbf{1 a}$. In particular, the dual binding with the PAS and CAS of ChE enzymes had previously been reported to contribute significantly to enzyme inhibitory activity. ${ }^{43}$ As for AChE, 2 a demonstrated a stronger binding affinity than neostigmine with BuChE $(-11.1 \mathrm{kcal} / \mathrm{mol}$ and $-6.9 \mathrm{kcal} / \mathrm{mol}$ respectively $)$ which reflected the in vitro results. 
Neostigmine was found to form no hydrogen bonding with BuChE but extensive hydrophobic interactions including $\pi-\pi$ bonding with Trp 82 (CAS). The comparison between neostigmine and $\mathbf{2 a}$ with regards to their inhibitory activity against cholinesterases agrees with the findings of Gao et al. ${ }^{43}$ whereby bulkier groups tend to exert the greatest activity against AChE and BuChE. As shown in Figure 2, neostigmine has a more compact structure when compared to $\mathbf{2 a}$ with only a single aromatic ring. In contrast, $\mathbf{2 a}$ forms additional interactions due to its three distinct aromatic ring systems and the propyl linker chain. Hence, it can develop a more stable complex with each ChE isoform.

Penetration across the blood brain barrier (BBB) is essential for compounds that aim to target the CNS, as for AD therapeutics. Given that lipophilicity is a key determinant for BBB permeability, computational predictions were performed to establish the $\log P$ and the likelihood that $\mathbf{2 a}$ would be able to penetrate the BBB. This lead structure $\mathbf{2 a}$ was found to have a $\log P$ of 4.52 , a promising lipophilicity for crossing the BBB in vivo. The BBB permeation properties of $\mathbf{2 a}$ supported the logP findings with a score of 0.036 . In order to have a high predicted ability of crossing the BBB, a structure must display a score of greater than $0.02 .{ }^{49}$

Taking together the above findings, novel compound $\mathbf{2 a}$ was identified as a lead structure for the multi-target strategy. It exhibited the strongest antioxidant activity overall due to its additional vanillin moiety, with an $\mathrm{IC}_{50}$ of $16.67 \mu \mathrm{M}$ in the DPPH assay, and 0.49 TE in the FRAP assay. It was also around 10 -fold more active than Trolox in the ORAC assay. Furthermore, 2a demonstrated the highest selectivity index for BuChE inhibition over AChE (SI of 53). It was able to inhibit BuChE in vitro with an activity 10 -fold greater than the known inhibitor, neostigmine. Although chain length was the major factor affecting AChE inhibition, molecular modelling studies demonstrated that compounds with bulkier structures as in $\mathbf{2 a}$ were found to exhibit greater BuChE selectivity. Compound $\mathbf{2 a}$ also exhibited promising predicted lipophilicity and BBB permeation properties. Overall, this work has demonstrated the novel application of vanillin derivatives as BuChE-selective inhibitors as well as strong antioxidants, representing a potential basis for the generation of multi-target AD therapeutics.

\section{Acknowledgement}

The authors would like to thank The Carnegie Trust for the Universities of Scotland for funding this work, and the EPSRC UK National Mass Spectrometry Service Centre at Swansea University, Swansea for mass spectral analysis. 


\section{References}

1. Chierrito TPC, Mantoani SP, Roca C, et al. From dual binding site acetylcholinesterase inhibitors to allosteric modulators: A new avenue for diseasemodifying drugs in Alzheimer's disease. Eur J Med Chem. 2017;139:773-791. doi:10.1016/j.ejmech.2017.08.051

2. Zala D, Chan D, McCrone P. The cost-effectiveness implications of suboptimal treatment for different severities of Alzheimer's disease in the UK. Int J Geriatr Psychiatry. 2018;33:307-315. doi:10.1002/gps.4745

3. Imtiaz $B$, Tolppanen $A$, Kivipelto $M$, Soininen $H$. Future directions in Alzheimer's disease from risk factors to prevention. Biochem Pharmacol. 2014;88:661-670. doi:10.1016/j.bcp.2014.01.003

4. Yiannopoulou KG, Papageorgiou SG. Current and future treatments for Alzheimer's disease. Ther Adv Neurol Disord. 2013;6:19-33. doi: $10.1177 / 1756285612461679$

5. Chen X, Pan W. The Treatment Strategies for Neurodegenerative Diseases by Integrative Medicine. Integr Med Int. 2015;1:223-225. doi: $10.1159 / 000381546$

6. Fish P V., Steadman D, Bayle ED, Whiting P. New approaches for the treatment of Alzheimer's disease. Bioorganic Med Chem Lett. 2019;29:125-133. doi:10.1016/j.bmcl.2018.11.034

7. Lane C, Hardy J, Schott J. Alzheimer's disease. Eur J Neurol. 2018;25:5970.

8. Blaikie L, Kay G, Kong Thoo Lin P. Current and emerging therapeutic targets of alzheimer's disease for the design of multi-target directed ligands. Medchemcomm. 2019;10:2052-2072. doi:10.1039/c9md00337a

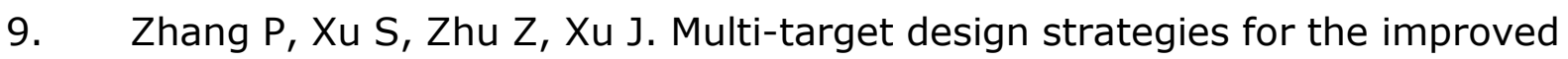
treatment of Alzheimer's disease. Eur J Med Chem. 2019;176:228-247.

10. Mesiti F, Chavarria D, Gaspar A, Alcaro S, Borges F. The chemistry toolbox of multitarget-directed ligands for Alzheimer's disease. Eur J Med Chem. $2019 ; 181: 1-16$.

11. Wang T, Liu X, Guan J, et al. Advancement of multi-target drug discoveries and promising applications in the field of Alzheimer's disease. Eur J Med Chem. 2019;169:200-223. doi:10.1016/j.ejmech.2019.02.076

12. Santos MA, Chand $\mathrm{K}$, Chaves $\mathrm{S}$. Recent progress in multifunctional metal chelators as potential drugs for Alzheimer's disease. Coord Chem Rev. 2016;327:287-303. doi:10.1016/j.ccr.2016.04.013 
13. Colovic MB, Krstic DZ, Lazarevic-Pasti TD, Bondzic AM, Vasic VM. Acetylcholinesterase Inhibitors: Pharmacology and Toxicology. Curr Neuropharmacol. 2013;11:315-355. doi:10.2174/1570159X11311030006

14. Drachman DA, Leavitt J. Human Memory and the Cholinergic System: A Relationship to Aging? Arch Neurol. 1974;30:113-121. doi:10.1001/archneur.1974.00490320001001

15. Perry EK, Perry RH, Blessed G, Tomlinson BE. Changes in Brain Cholinesterases in Senile Dementia of Alzheimer Type. Neuropathol Appl Neurobiol. 1978;4:273-277. doi:10.1111/j.1365-2990.1978.tb00545.x

16. Greig NH, Utsuki T, Yu QS, et al. A new therapeutic target in Alzheimer's disease treatment: Attention to butyrylcholinesterase. Curr Med Res Opin. 2001;17:159-165. doi:10.1185/03007990152673800

17. Darvesh S. Butyrylcholinesterase as a Diagnostic and Therapeutic Target for Alzheimer's Disease. Curr Alzheimer Res. 2016;13:1173-1177. doi: $10.2174 / 1567205013666160404120542$

18. Nordberg A, Ballard C, Bullock R, Darreh-Shori T, Somogyi M. A review of butyrylcholinesterase as a therapeutic target in the treatment of Alzheimer's disease. Prim Care Companion J Clin Psychiatry. 2013;15:1-16. doi:10.4088/PCC.12r01412

19. Mesulam MM, Guillozet A, Shaw P, Levey A, Duysen EG, Lockridge O. Acetylcholinesterase knockouts establish central cholinergic pathways and can use butyrylcholinesterase to hydrolyze acetylcholine. Neuroscience. 2002;110:627639. doi:10.1016/S0306-4522(01)00613-3

20. Reid GA, Darvesh S. Butyrylcholinesterase-knockout reduces brain deposition of fibrillar $\beta$-amyloid in an Alzheimer mouse model. Neuroscience. 2015;298:424-435. doi:10.1016/j.neuroscience.2015.04.039

21. Perry E, Bergmann K, Tomlinson BE, Blessed G, Gibson PH, Perry RH. Correlation of cholinergic abnormalities with senile plaques and mental test scores in senile dementia. Br Med J. 1978;2:1457. doi:10.1136/bmj.2.6150.1457

22. Yu QS, Holloway HW, Utsuki T, Brossi A, Greig NH. Synthesis of novel phenserine-based-selective inhibitors of butyrylcholinesterase for Alzheimer's disease. J Med Chem. 1999;42:1855-1861. doi:10.1021/jm980459s

23. Bosak A, Ramić $A$, Šmidlehner $T$, Hrenar $T$, Primožič I, Kovarik Z. Design and evaluation of selective butyrylcholinesterase inhibitors based on Cinchona alkaloid scaffold. PLoS One. 2018;13:1-18. doi:10.1371/journal.pone.0205193

24. Brus B, Košak $U$, Turk $S$, et al. Discovery, biological evaluation, and crystal structure of a novel nanomolar selective butyrylcholinesterase inhibitor. J Med Chem. 2014;57:8167-8179. doi:10.1021/jm501195e 
25. Greig $\mathrm{NH}$, Utsuki $\mathrm{T}$, Ingram $\mathrm{DK}$, et al. Selective butyrylcholinesterase inhibition elevates brain acetylcholine, augments learning and lowers Alzheimer $\beta$-amyloid peptide in rodent. Proc Natl Acad Sci U S A. 2005;102:17213-17218. doi:10.1073/pnas.0508575102

26. Kumar A, Pintus F, Di Petrillo A, et al. Novel 2-pheynlbenzofuran derivatives as selective butyrylcholinesterase inhibitors for Alzheimer's disease. Sci Rep. 2018;8:1-12. doi: 10.1038/s41598-018-22747-2

27. Sawatzky E, Wehle S, Kling B, et al. Discovery of Highly Selective and Nanomolar Carbamate-Based Butyrylcholinesterase Inhibitors by Rational Investigation into Their Inhibition Mode. J Med Chem. 2016;59:2067-2082. doi:10.1021/acs.jmedchem.5b01674

28. Macklin LJ, Schwans JP. Synthesis, biochemical evaluation, and molecular modeling of organophosphate-coumarin hybrids as potent and selective butyrylcholinesterase inhibitors. Bioorganic Med Chem Lett. 2020;30:127213. doi:10.1016/j.bmcl.2020.127213

29. Ha ZY, Mathew S, Yeong KY. Butyrylcholinesterase: A Multifaceted Pharmacological Target and Tool. Curr Protein Pept Sci. 2019;21:99-109. doi:10.2174/1389203720666191107094949

30. Francis PT, Palmer AM, Snape M, Wilcock GK. The cholinergic hypothesis of Alzheimer's disease: A review of progress. J Neurol Neurosurg Psychiatry. 1999;66:137-147. doi:10.1136/jnnp.66.2.137

31. Markesbery W. Oxidative Stress Hypothesis in Alzheimer's Disease. Free Radic Biol Med. 1997;23:134-147.

32. Evans $\mathrm{PH}$. Free radicals in brain metabolism and pathology. $\mathrm{Br}$ Med Bull. 1993;49:577-587. doi:10.1093/oxfordjournals.bmb.a072632

33. Behl C, Davis JB, Lesley R, Schubert D. Hydrogen peroxide mediates amyloid $\beta$ protein toxicity. Cell. 1994;77:817-827. doi:10.1016/00928674(94)90131-7

34. Dias-Santagata D, Fulga TA, Duttaroy A, Feany MB. Oxidative stress mediates tau-induced neurodegeneration in Drosophila. $J$ Clin Invest. 2007; 117:236-245. doi:10.1172/JCI28769

35. Ramsay RR, Popovic-Nikolic MR, Nikolic K, Uliassi E, Bolognesi ML. A perspective on multi-target drug discovery and design for complex diseases. Clin Transl Med. 2018;7:1-18. doi:10.1186/s40169-017-0181-2

36. Carreiras M, Mendes E, Perry M, Francisco A, Marco-Contelles J. The Multifactorial Nature of Alzheimer's Disease for Developing Potential Therapeutics. Curr Top Med Chem. 2014;13:1745-1770. doi:10.2174/15680266113139990135 
37. Bansal Y, Silakari O. Multifunctional compounds: Smart molecules for multifactorial diseases. Eur J Med Chem. 2014;76:31-42. doi:10.1016/j.ejmech.2014.01.060

38. Shoeb A, Chowta MN, Pallempati G, Rai A, Singh A. Evaluation of antidepressant activity of vanillin in mice. Indian J Pharmacol. 2013;45:141-144. doi: $10.4103 / 0253-7613.108292$

39. Iannuzzi C, Borriello M, Irace G, Cammarota M, Di Maro A, Sirangelo I. Vanillin Affects Amyloid Aggregation and Non-Enzymatic Glycation in Human Insulin. Sci Rep. 2017;7:1-14. doi:10.1038/s41598-017-15503-5

40. Kundu A, Mitra A. Flavoring Extracts of Hemidesmus indicus Roots and Vanilla planifolia Pods Exhibit In vitro Acetylcholinesterase Inhibitory Activities. Plant Foods Hum Nutr. 2013;68:247-253. doi:10.1007/s11130-013-0363-z

41. Scipioni M, Kay G, Megson I, Kong P, Lin T. Novel vanillin derivatives: Synthesis, anti-oxidant, DNA and cellular protection properties. Eur J Med Chem. 2018;143:745-754. doi:10.1016/j.ejmech.2017.11.072

42. Scipioni M, Kay G, Megson L, Kong P, Lin T. Synthesis of novel vanillin derivatives: novel multi-targeted scaffold ligands against Alzheimer's disease. Medchemcomm. 2019;10:764-777. doi:10.1039/c9md00048h

43. Gao J, Midde N, Zhu J, Terry A V., McInnes C, Chapman JM. Synthesis and biological evaluation of ranitidine analogs as multiple-target-directed cognitive enhancers for the treatment of Alzheimer's disease. Bioorganic Med Chem Lett. 2016;26:5573-5579. doi:10.1016/j.bmcl.2016.09.072

44. Košak U, Knez D, Brus B, et al. N-Propargylpiperidines with naphthalene-2carboxamide or naphthalene-2-sulfonamide moieties: Potential multifunctional anti-Alzheimer's agents. Bioorganic Med Chem. 2017;25:633-645. doi:10.1016/j.bmc.2016.11.032

45. Si W, Zhang T, Zhang $L$, et al. Design, synthesis and bioactivity of novel phthalimide derivatives as acetylcholinesterase inhibitors. Bioorganic Med Chem Lett. 2016;26:2380-2382. doi:10.1016/j.bmcl.2015.07.052

46. Lamie PF, Philoppes JN, El-Gendy AO, Rarova L, Gruz J. Design, synthesis and evaluation of novel phthalimide derivatives as in vitro anti-microbial, antioxidant and anti-inflammatory agents. Molecules. 2015;20:16620-16642. doi: $10.3390 /$ molecules 200916620

47. Ellman GL, Courtney KD, Andres V, Featherstone RM. A new and rapid colorimetric determination of acetylcholinesterase activity. Biochem Pharmacol. 1961;7:88-95. doi:10.1016/0006-2952(61)90145-9

48. Trott O, Olson AJ. AutoDock Vina: Improving the Speed and Accuracy of Docking with a New Scoring Function, Efficient Optimization, and Multithreading. J Comput Chem. 2010;31:455-461. doi:10.1002/jcc.21334 
49. Liu H, Wang L, Lv M, et al. AlzPlatform: An Alzheimer's disease domainspecific chemogenomics knowledgebase for polypharmacology and target identification research. J Chem Inf Model. 2014;54:1050-1060. doi:10.1021/ci500004h

50. Noro J, Maciel J, Duarte D, et al. Evaluation of New Naphthalimides as Potential Anticancer Agents against Breast Cancer MCF-7, Pancreatic Cancer BxPC-3 and Colon Cancer HCT- 15 Cell Lines. Org Chem Curr Res. 2015;4:1-11. doi: $10.4172 / 2161-0401.1000144$

51. Horii ZI, Iwat A C, Tamura Y. Reduction of Phthalimides with Sodium Borohydride. J Org Chem. 1961;26:2273-2276. doi:10.1021/jo01351a031

52. Payet B, Sing ASC, Smadja J. Assessment of antioxidant activity of cane brown sugars by ABTS and DPPH radical scavenging assays: Determination of their polyphenolic and volatile constituents. J Agric Food Chem. 2005;53:10074-10079. doi: $10.1021 /$ jf0517703

53. Firuzi O, Lacanna A, Petrucci R, Marrosu G, Saso L. Evaluation of the antioxidant activity of flavonoids by "ferric reducing antioxidant power" assay and cyclic voltammetry. Biochim Biophys Acta - Gen Subj. 2005;1721:174-184. doi:10.1016/j.bbagen.2004.11.001

54. Huang D, Ou B, Hampsch-Woodill M, Flanagan JA, Prior RL. High-throughput assay of oxygen radical absorbance capacity (ORAC) using a multichannel liquid handling system coupled with a microplate fluorescence reader in 96-well format. J Agric Food Chem. 2002;50:4437-4444. doi:10.1021/jf0201529

55. Li Z, Mu C, Wang B, Jin J. Graveoline analogs exhibiting selective acetylcholinesterase inhibitory activity as potential lead compounds for the treatment of Alzheimer's disease. Molecules. 2016;21:1-11. doi: $10.3390 /$ molecules 21020132

56. Dighe SN, Deora GS, De La Mora E, et al. Discovery and structure-activity relationships of a highly selective butyrylcholinesterase inhibitor by Structurebased virtual screening. J Med Chem. 2016;59:7683-7689. doi:10.1021/acs.jmedchem.6b00356 
APPENDIX. SUPPLEMENTARY DATA

\title{
Synthesis and in vitro evaluation of vanillin derivatives as multi-target therapeutics for the treatment of Alzheimer's disease
}

\author{
Laura Blaikie, Graeme Kay, Paul Kong Thoo Lin \\ School of Pharmacy and Life Sciences, Robert Gordon University, Aberdeen, \\ Scotland
}

\section{EXPERIMENTAL SECTION}

\section{Materials}

All reagents were purchased from Sigma-Aldrich and Fischer Scientific unless otherwise stated. NMR spectra $\left({ }^{1} \mathrm{H}\right.$ and $\left.{ }^{13} \mathrm{C}\right)$ were generated using a Magnet Ultrashield Bruker $400 \mathrm{MHz}$ spectrometer. Low-resolution mass spectrometry was performed using an Agilent 6130 Quadrupole LCMS System with 1200 Series HPLC System. High-resolution mass spectrometry was performed at EPSRC National Mass Spectrometry Service Centre at Swansea University, Swansea, using a Thermo Scientific LTQ Orbitrap XL spectrometer. The progress of the reaction was monitored using thin layer chromatography (TLC) on aluminium foil silica gel 60 plates with $254 \mathrm{~nm}$ fluorescence indicator, and visualised using a UV light box (254-256 nm). Column chromatography was performed using silica gel (Alfa Aesar 70-230 mesh) as the stationary phase and chloroform/methanol as the mobile phase. Measurements for the in vitro assays were performed using a BioRad iMark microplate reader, aside from the ORAC assay which was monitored using a BioTek Synergy HT microplate reader. All assays were carried out in triplicate, and calculations (for $\mathrm{IC}_{50}$ and TE values, and standard deviation analyses) were performed in Microsoft Excel. Chemical drawings were constructed using ChemDraw Professional 16.0 software. Chem3D 16.0 software with the MM2 force field energy minimisation tool was used to prepare the ligands for the computational studies. PyRx with AutoDock Vina was used to perform the binding affinity calculations, and PyMol Molecular Graphics System was used to visualise the docking conformations of the ligands in the enzyme targets. 


\section{Chemical Synthesis}

General procedure for the synthesis of $\mathbf{1 a}, \mathbf{1} \boldsymbol{b}$, and $\mathbf{2 a}$

For $\mathbf{1 a}$ and $\mathbf{2 a}$, diaminopropane $(1.5 \mathrm{~g}, 20.18 \mathrm{mmol})$ and naphthalic anhydride ( $2 \mathrm{~g}, 10.09 \mathrm{mmol}$ ) were reacted in ethanol on reflux for an hour. For $\mathbf{1 b}$, diaminohexane $(1.45 \mathrm{~g}, 12.48 \mathrm{mmol})$ and naphthalic anhydride $(1.25 \mathrm{~g}, 6.31$ $\mathrm{mmol})$ were reacted as above. The mixture was then cooled to room temperature and the precipitate that formed was filtered off (bis-naphthalimide by-product). The solvent from the resulting filtrate was removed using RFE and the residue was treated with diethyl ether to obtain a solid which was washed thoroughly with ether. This solid was the intermediate aminopropyl- or hexylnaphthalimide. Once dried in the vac oven, the intermediate was reacted with vanillin as follows.

Synthesis of 2-(3-((4-hydroxy-3-methoxybenzyl)amino)propyl)-1Hbenzo[de]isoquinoline-1,3(2H)-dione - 1 a

The aminopropylnaphthalimide intermediate $(1 \mathrm{~g}, 3.93 \mathrm{mmol})$ was dissolved in methanol with vanillin $(0.65 \mathrm{~g}, 4.33 \mathrm{mmol})$ and stirred at room temperature for 24 hours. Sodium borohydride $(0.17 \mathrm{~g}, 4.72 \mathrm{mmol})$ was then added, and the reaction was left to stir for a further 4 hours. The resulting precipitate formed was filtered off and washed thoroughly with water. Further purification was performed via recrystallisation with ethanol to afford a pale yellow solid (yield: 85\%). ${ }^{1} \mathrm{HNMR}$ : $\left(\mathrm{CDCl}_{3}\right.$ solvent peak $\left.\delta: 7.30\right), 8.65-6.83(\mathrm{~m}, \mathrm{Ar}-\underline{\mathrm{H}}, 9 \mathrm{H}), 4.34-$ $4.31\left(\mathrm{t}, \mathrm{NC}_{2}{ }_{2}-\mathrm{CH}_{2}, \mathrm{~J}=6.8 \mathrm{~Hz}, 2 \mathrm{H}\right), 3.92\left(\mathrm{~s},-\mathrm{OC}_{3}, 3 \mathrm{H}\right), 3.77\left(\mathrm{~s}, \mathrm{Ar}-\mathrm{C}_{2}-\mathrm{N}_{2}, 2 \mathrm{H}\right)$, 2.78-2.75 (t, $\left.\mathrm{CH}_{2}-\underline{\mathrm{C}}_{2}-\mathrm{N}, \mathrm{J}=6.8 \mathrm{~Hz}, 2 \mathrm{H}\right), 2.06-2.03\left(\mathrm{~m}, \mathrm{CH}_{2}-\mathrm{C}_{2}-\mathrm{CH}_{2}, \mathrm{~J}=6.8\right.$ $\mathrm{Hz}, 2 \mathrm{H}) .{ }^{13} \mathrm{CNMR}$ : $\left(\mathrm{CDCl}_{3}\right.$ solvent peak $\delta:$ 77.3-76.7) 164.3, 146.6-111.0, 55.8, 53.6, 46.2, 38.2, 28.0. HRMS calcd for $\mathrm{C}_{23} \mathrm{H}_{23} \mathrm{~N}_{2} \mathrm{O}_{4}[\mathrm{M}+\mathrm{H}]^{+} 391.1652, \mathrm{~m} / z$ found 391.1651 .

Synthesis of 2-(6-((4-hydroxy-3-methoxybenzyl)amino)hexyl)-1Hbenzo[de]isoquinoline-1,3(2H)-dione - $1 \boldsymbol{b}$

The aminohexylnaphthalimide intermediate $(1.13 \mathrm{~g}, 3.81 \mathrm{mmol})$ was dissolved in methanol with vanillin $(0.64 \mathrm{~g}, 4.21 \mathrm{mmol})$ and stirred at room temperature for 24 hours. Sodium borohydride $(0.17 \mathrm{~g}, 4.72 \mathrm{mmol})$ was then added, and the reaction was left to stir for a further 4 hours. The resulting precipitate formed was filtered off and washed thoroughly with water. Further purification was performed via recrystallisation with ethanol to afford a pale yellow solid (yield: 74\%). ${ }^{1} H N M R$ : $\left(\mathrm{CDCl}_{3}\right.$ solvent peak $\left.\delta: 7.19\right), 8.50-6.65$ (m, Ar- $\left.\underline{\mathrm{H}}, 9 \mathrm{H}\right), 4.09-$ $4.06\left(\mathrm{t}, \mathrm{NC}_{2}-\mathrm{CH}_{2}, \mathrm{~J}=7.6 \mathrm{~Hz}, 2 \mathrm{H}\right), 3.73\left(\mathrm{~s},-\mathrm{OC}_{3}, 3 \mathrm{H}\right), 3.62\left(\mathrm{~s}, \mathrm{Ar}-\mathrm{C}_{2}-\mathrm{H}_{1}, 2 \mathrm{H}\right)$, 2.57-2.53 (t, $\left.\mathrm{CH}_{2}-\underline{\mathrm{C}}_{2}-\mathrm{N}, \mathrm{J}=7.2 \mathrm{~Hz}, 2 \mathrm{H}\right), 1.66-1.63\left(\mathrm{t}, \mathrm{CH}_{2}-\mathrm{C}_{2}-\mathrm{CH}_{2}, \mathrm{~J}=7.2\right.$ $\mathrm{Hz}, 2 \mathrm{H}), 1.49-1.47\left(\mathrm{t}, \mathrm{CH}_{2}-\mathrm{CH}_{2}-\mathrm{CH}_{2}, \mathrm{~J}=7.2 \mathrm{~Hz}, 2 \mathrm{H}\right), 1.34-1.31\left(\mathrm{~m}, \mathrm{CH}_{2}-\mathrm{C}_{2}-\right.$ $\left.\mathrm{CH}_{2}-\mathrm{CH}_{2}, \mathrm{~J}=3.2 \mathrm{~Hz}, 4 \mathrm{H}\right) .{ }^{13} \mathrm{CNMR}:\left(\mathrm{CDCl}_{3}\right.$ solvent peak $\left.\delta: 77.4-76.7\right) 164.2$, 146.8-111.0, 55.8, 53.8, 49.1, 40.3, 29.6, 28.0, 27.0, 27.0. LRMS calcd for $\mathrm{C}_{26} \mathrm{H}_{28} \mathrm{~N}_{2} \mathrm{O}_{4}[\mathrm{M}+\mathrm{H}]^{+} 433.2, \mathrm{~m} / \mathrm{z}$ found 433.2. 
Synthesis of 2-(3-(bis(4-hydroxy-3-methoxybenzyl)amino)propyl)-1Hbenzo[de]isoquinoline-1,3(2H)-dione - $\mathbf{2 a}$

The aminopropylnaphthalimide intermediate $(0.5 \mathrm{~g}, 2 \mathrm{mmol})$ was reacted with vanillin $(0.23 \mathrm{~g}, 1.51 \mathrm{mmol})$ in methanol in the presence of zinc chloride $(0.21 \mathrm{~g}$, $1.54 \mathrm{mmol})$ and sodium cyanoborohydride $(0.09 \mathrm{~g}, 1.51 \mathrm{mmol})$ in a reductive amination reaction. This was stirred overnight on reflux. Once cooled, the solvent was removed using RFE and the residue was dissolved in chloroform. This was then subjected to column chromatography to afford an orange solid (yield: 6\%). ${ }^{1} \mathrm{HNMR}$ : $\left(\mathrm{CDCl}_{3}\right.$ solvent peak $\left.\delta: 7.18\right), 8.49-6.68(\mathrm{~m}, \mathrm{Ar}-\underline{\mathrm{H}}, 12 \mathrm{H})$, 4.13-4.09 (t, $\left.\mathrm{NC}_{2}-\mathrm{CH}_{2}, \mathrm{~J}=7.6 \mathrm{~Hz}, 2 \mathrm{H}\right), 3.83\left(\mathrm{~s},-\mathrm{OCH}_{3}, 6 \mathrm{H}\right), 3.42\left(\mathrm{~s}, \mathrm{Ar}-\mathrm{C}_{2}-\mathrm{N}\right.$, $4 \mathrm{H}), 2.50-2.47\left(\mathrm{t}, \mathrm{CH}_{2}-\mathrm{C}_{2}-\mathrm{N}, \mathrm{J}=6.4 \mathrm{~Hz}, 2 \mathrm{H}\right), 1.89-1.87\left(\mathrm{~m}, \mathrm{CH}_{2}-\mathrm{C}_{2}-\mathrm{CH}_{2}, \mathrm{~J}=\right.$ $7.6 \mathrm{~Hz}, 2 \mathrm{H}) .{ }^{13} \mathrm{CNMR}$ : $\left(\mathrm{CDCl}_{3}\right.$ solvent peak $\left.\delta: 77.4-76.7\right) 164.1,146.4-111.4$, $57.8,55.9,50.5,38.9,25.4$. HRMS calcd for $\mathrm{C}_{31} \mathrm{H}_{30} \mathrm{~N}_{2} \mathrm{O}_{6}[\mathrm{M}+\mathrm{H}]^{+} 527.2177, \mathrm{~m} / \mathrm{z}$ found 527.2166 .

\section{General procedure for the synthesis of $\mathbf{3 a}$ and $\mathbf{4 a}$}

For the synthesis of the hexyl phthalimide derivative (3a), Boc-hexyldiamine $(0.50 \mathrm{~g}, 2.3 \mathrm{mmol})$ was dissolved in ethanol and phthalic anhydride was added to the solution $(0.34 \mathrm{~g}, 2.3 \mathrm{mmol})$. For $\mathbf{4 a}$, Boc-propyldiamine $(0.51 \mathrm{~g}, 2.93$ $\mathrm{mmol}$ ) and phthalic anhydride $(0.44 \mathrm{~g}, 2.93)$ was stirred in ethanol. The reaction was refluxed for an hour. Once cooled, the solvent was removed using RFE and the residue was dissolved in dioxane with $\mathrm{HCl}(3 \mathrm{~mL}$ dioxane and $4 \mathrm{~mL} \mathrm{HCl}$ in dioxane). It was stirred at room temperature for 2 hours. The solid salt formed was filtered and washed with dioxane and dried in the vacuum oven. The salt was dissolved in methanol and triethylamine was added ( $3 x$ excess). The free base was then dried thoroughly. This afforded the aminopropyl- or hexylphthalimide intermediate, which was consequently reacted with vanillin as follows.

Synthesis of 2-(6-((4-hydroxy-3-methoxybenzyl)amino)hexyl)isoindoline-1,3dione - $3 a$

The aminohexylphthalimide intermediate $(0.4 \mathrm{~g}, 1.62 \mathrm{mmol})$ was dissolved in methanol with vanillin $(0.24 \mathrm{~g}, 1.62 \mathrm{mmol})$ and stirred at room temperature for 24 hours. Sodium borohydride $(0.20 \mathrm{~g}, 5.28 \mathrm{mmol})$ was then added, and the reaction was left to stir for a further 4 hours. The solvent was removed using RFE and the resulting residue was washed thoroughly with water. Further purification was performed via column chromatography to afford an orange/brown solid (yield: 8\%). ${ }^{1} \mathrm{HNMR}$ : ( $\mathrm{CDCl}_{3}$ solvent peak $\left.\delta: 7.20\right)$, 7.74$6.64(\mathrm{~m}, \mathrm{Ar}-\underline{\mathrm{H}}, 7 \mathrm{H}), 3.69\left(\mathrm{~s},-\mathrm{OC}_{3}, 3 \mathrm{H}\right), 3.62\left(\mathrm{~s}, \mathrm{Ar}-\mathrm{C}_{2}-\mathrm{N}, 2 \mathrm{H}\right), 3.58-3.55$ (t, $\left.\mathrm{NC}_{2}-\mathrm{CH}_{2}, \mathrm{~J}=7.2 \mathrm{~Hz}, 2 \mathrm{H}\right), 2.56-2.53\left(\mathrm{t}, \mathrm{CH}_{2}-\mathrm{CH}_{2}-\mathrm{N}, \mathrm{J}=7.2 \mathrm{~Hz}, 2 \mathrm{H}\right), 1.58-1.55$ (t, $\left.\mathrm{CH}_{2}-\mathrm{C}_{2}-\mathrm{CH}_{2}, \mathrm{~J}=6.8 \mathrm{~Hz}, 2 \mathrm{H}\right), 1.47-1.42\left(\mathrm{~m}, \mathrm{CH}_{2}-\mathrm{C}_{2}-\mathrm{CH}_{2}, \mathrm{~J}=6.8 \mathrm{~Hz}, 2 \mathrm{H}\right)$, 1.26-1.25 (m, $\left.\mathrm{CH}_{2}-\mathrm{C}_{2}-\mathrm{C}_{2}-\mathrm{CH}_{2}, \mathrm{~J}=3.2 \mathrm{~Hz}, 4 \mathrm{H}\right) .{ }^{13} \mathrm{CNMR}$ : $\left(\mathrm{CDCl}_{3}\right.$ solvent peak ס: 77.4-76.8) 168.4, 147.0-111.3, 55.7, 53.3, 48.7, 38.0, 29.1, 28.5, 26.8, 26.8. HRMS calcd for $\mathrm{C}_{22} \mathrm{H}_{26} \mathrm{~N}_{2} \mathrm{O}_{4}[\mathrm{M}+\mathrm{H}]^{+} 383.1965, \mathrm{~m} / z$ found 383.1963 . 
Synthesis of N-(3-((4-hydroxy-3-methoxybenzyl)amino)propyl)-2-

(hydroxymethyl)benzamide - 4a

The aminopropylphthalimide intermediate $(0.3 \mathrm{~g}, 1.65 \mathrm{mmol})$ was dissolved in methanol with vanillin $(0.25 \mathrm{~g}, 1.65 \mathrm{mmol})$ and stirred at room temperature for 24 hours. Sodium borohydride $(0.18 \mathrm{~g}, 4.95 \mathrm{mmol})$ was then added, and the reaction stirred on reflux for a further 4 hours. The solvent was removed using RFE and the resulting residue was dissolved in chloroform and extracted 3 times with water. Further purification was performed via column chromatography to afford a pale brown solid (yield: $8 \%) .{ }^{1} \mathrm{HNMR}$ : $\left(\mathrm{CDCl}_{3}\right.$ solvent peak $\left.\delta: 7.19\right)$, 7.80-6.72 (m, Ar- $\left.\underline{H}_{1} 7 \mathrm{H}\right), 4.29$ (s, Ar- $\left.\underline{\mathrm{H}}_{2}-\mathrm{OH}, 2 \mathrm{H}\right), 3.81$ (s, Ar- $\left.\underline{\mathrm{C}}_{2}-\mathrm{N}, 2 \mathrm{H}\right), 3.74-$ $3.71\left(\mathrm{~m}, \mathrm{NC}_{2}-\mathrm{CH}_{2}, \mathrm{~J}=5.6 \mathrm{~Hz}, 4 \mathrm{H}\right), 3.29\left(\mathrm{~s},-\mathrm{OC}_{3}, 3 \mathrm{H}\right), 1.93-1.90\left(\mathrm{t}, \mathrm{CH}_{2}-\mathrm{C}_{2}-\right.$ $\left.\mathrm{CH}_{2}, \mathrm{~J}=5.6 \mathrm{~Hz}, 2 \mathrm{H}\right) .{ }^{13} \mathrm{CNMR}$ : $\left(\mathrm{CDCl}_{3}\right.$ solvent peak $\left.\delta: 77.4-76.7\right) 166.7,150.7-$ $110.5,74.7,55.9,51.6,45.9,37.2,20.4$. LRMS calcd for $\mathrm{C}_{19} \mathrm{H}_{24} \mathrm{~N}_{2} \mathrm{O}_{5}[\mathrm{M}+\mathrm{H}]^{+}$ $361.4, \mathrm{~m} / \mathrm{z}$ found $187.1=\left[\mathrm{M}^{+}-196\right]+\mathrm{Na}^{+}$.

\section{In Vitro Evaluation}

\section{DPPH assay}

The free radical scavenging capabilities of the synthesised compounds were determined following the procedure reported by Payet et al. ${ }^{1}$ with some modifications in a 96-well plate. A dilution series of the compounds from $10 \mathrm{mM}$ DMSO stocks was prepared in methanol, and $50 \mu \mathrm{L}$ of each were transferred to the corresponding well. Methanol $(50 \mu \mathrm{L})$ was used as a negative control with DMSO content equivalent to the highest DMSO concentration in the compound solutions (no greater than 1\% DMSO). DPPH solution ( $100 \mu \mathrm{L}, 0.1 \mathrm{mM}$ ) was added to each well followed by a 30-minute incubation in the dark. The absorbance was then measured at $490 \mathrm{~nm}$.

FRAP assay

The reducing power of the novel compounds was tested using the FRAP assay following the method described by Firuzi et al. ${ }^{2}$ with minor modifications in a 96well set-up. FRAP reagent was prepared by combining $2.5 \mathrm{~mL}$ of $10 \mathrm{mM}$ TPTZ (in $40 \mathrm{mM} \mathrm{HCl}$ ) with $2.5 \mathrm{~mL}$ of $20 \mathrm{mM} \mathrm{FeCl}_{3}$ (in deionized water) in $300 \mathrm{mM}$ sodium acetate buffer ( $\mathrm{pH} \mathrm{3.6)}$ with the volume made up to $30 \mathrm{~mL}$. A dilution series of the compounds (from $10 \mathrm{mM}$ DMSO stocks) and Trolox was made in ethanol/water and $10 \mu \mathrm{L}$ of each was pipetted into the corresponding well, along with $190 \mu \mathrm{L}$ of FRAP reagent. The plate was stored in the dark for 30 minutes. The absorbance was then measured at $595 \mathrm{~nm}$. 
ORAC assay

The ORAC assay was employed to assess the ability of the compounds to prevent oxidative degradation of fluorescein following the method previously reported by Huang et al. ${ }^{3}$ with minor modifications on a black-walled 96 -well plate. A dilution series of the synthesised compounds (from $10 \mathrm{mM}$ DMSO stocks) and Trolox was made in phosphate buffer ( $75 \mathrm{mM}, \mathrm{pH} 7.4)$, and $25 \mu \mathrm{L}$ of each was transferred into the corresponding well. Phosphate buffer ( $25 \mu \mathrm{L})$ was to the control wells. Sodium fluorescein solution (150 $\mu \mathrm{L}, 25 \mathrm{nM})$ was added to each well, and the plate was incubated for 30 minutes at $37^{\circ} \mathrm{C}$. Next, $25 \mu \mathrm{L}$ of AAPH solution $(0.15 \mathrm{M})$ was added to the positive control and sample wells, while $25 \mu \mathrm{L}$ of phosphate buffer was added to the fluorescein control. The fluorescence was then measured every 2 minutes over a period of 2 hours (485/20 nm excitation, 525/20 nm emission).

\section{Ellman's assay}

The inhibitory activity of the novel compounds against AChE and BuChE was determined using the Ellman method with some modifications. ${ }^{4}$ Stock solutions of AChE and BuChE (22 U/mL) from Electrophorus electricus and equine serum respectively were prepared in $20 \mathrm{mM}$ Tris $\mathrm{HCl}(\mathrm{pH} 7.5)$. Prior to use, the AChE stock solution was diluted $1 / 100$, and BuChE by $3 / 100$. A 3 mM DTNB (5,5'dithiobis-(2-nitrobenzoic acid)) solution was prepared by dissolving $0.1189 \mathrm{~g}$ of DTNB in phosphate/Hepes buffer (0.05 M/0.09 M, pH 7.5). Solutions of $15 \mathrm{mM}$ acetylthiocholine iodide and butyrylthiocholine iodide were prepared in deionized water. A dilution series of the compounds was made in methanol, and $25 \mu \mathrm{L}$ of each was pipetted into the corresponding well, along with $125 \mu \mathrm{L}$ of DTNB solution and $25 \mu \mathrm{L}$ of diluted AChE or BuChE solution. Methanol ( $25 \mu \mathrm{L}$ ) was added in the control wells. The plate was incubated for 10 minutes at $37^{\circ} \mathrm{C}$, then $25 \mu \mathrm{L}$ of acetylthiocholine iodide or butyrylthiocholine iodide solution was added to each well and the plate was incubated for a further 10 minutes. The absorbance was then measured at $415 \mathrm{~nm}$. 


\section{In Silico Evaluation}

\section{Molecular modelling}

In silico predictions for the binding potential of the compounds against ChE enzymes were performed using the molecular modelling software, PyRx. The protein structures employed for the docking procedures were obtained from the Protein Data Bank (AChE - 4PQE; BuChE - 2J4C). Both structures had sufficient resolutions (less than $3 \AA$ ). Water molecules and any ligands attached to the structures were removed, and polar hydrogens were added. The 3D structure of the synthesised compounds was generated using ChemDraw (ChemDraw Professional 16.0 and Chem3D 16.0) and the MM2 energy minimisation tool, and the structures were saved as pdb files. Each ligand with its respective macromolecule were loaded into PyRx, and Autodock Vina $1.1 .2^{5}$ was used to calculate the binding energies of the various possible conformations. The molecules were prepared for docking by positioning the grid box around the binding site. The position of the binding site was determined by using a residue that is critical to ligand binding in the enzyme active site, as previously reported. The grid box was then set to size $(40 \times 40 \times 40 \AA)$. The lowest energy conformation for each ligand-macromolecule complex was selected for further analysis, and the complex was loaded into PyMol (PyMol Molecular Graphics System, version 2.3.3, Schrodinger, LLC) for visualisation.

\section{LogP calculations}

The ability of the compound to be absorbed by the body was predicted by calculating its logP value. This calculation was carried out using ChemDraw Professional 16.0. Compounds had to have a logP value of less than 5 to be deemed as likely to be absorbed in the BBB.

\section{BBB permeation properties}

The BBB permeation properties of the compounds were analysed using the online BBB prediction server provided by Liu et al. ${ }^{5}$ The compound structures were drawn within the website (https://www.cbligand.org/BBB/), and the scores for BBB permeation were determined using the SVM (support vector machine) algorithm along with the MAACS fingerprint. To be classified as having high BBB permeation properties, a score of greater than 0.02 had to be determined. 


\section{Additional results}

Binding affinities for all compounds and positive control, neostigmine, in ChE enzymes:

\begin{tabular}{|c|c|c|}
\hline Compound & AChE (kcal/mol) & BuChE (kcal/mol) \\
\hline $1 \mathbf{a}$ & -10.8 & -10.3 \\
\hline $1 \mathbf{b}$ & -10.7 & -10.3 \\
\hline $2 a$ & -11.3 & -11.1 \\
\hline $3 \mathbf{a}$ & -9.2 & -9.3 \\
\hline $4 a$ & -9.1 & -8.5 \\
\hline Neostigmine & -7.0 & -6.9 \\
\hline
\end{tabular}


NMR and MS Spectra for the Synthesised Compounds

\section{Compound 1 a}
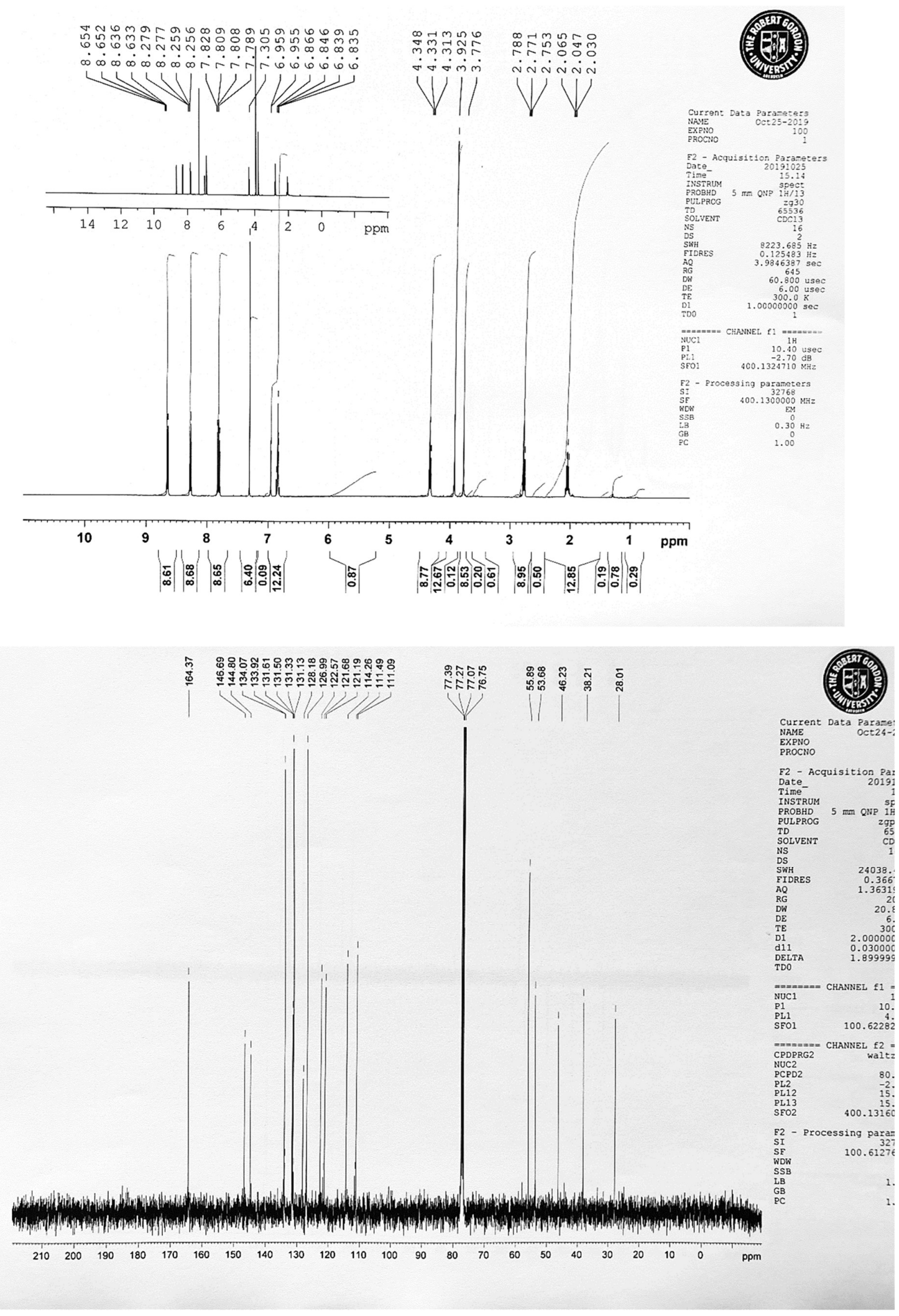


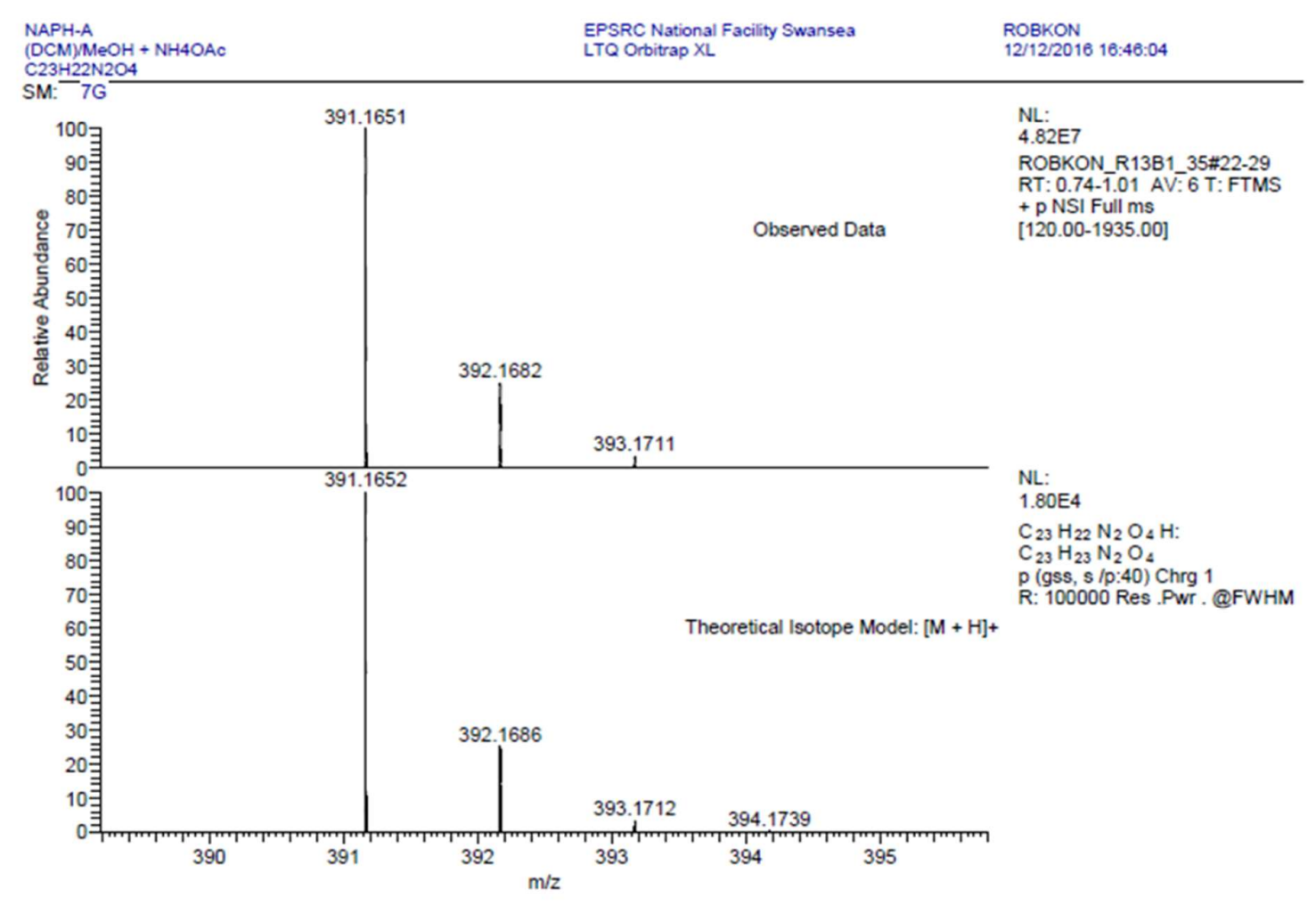




\section{Compound $1 \mathbf{b}$}
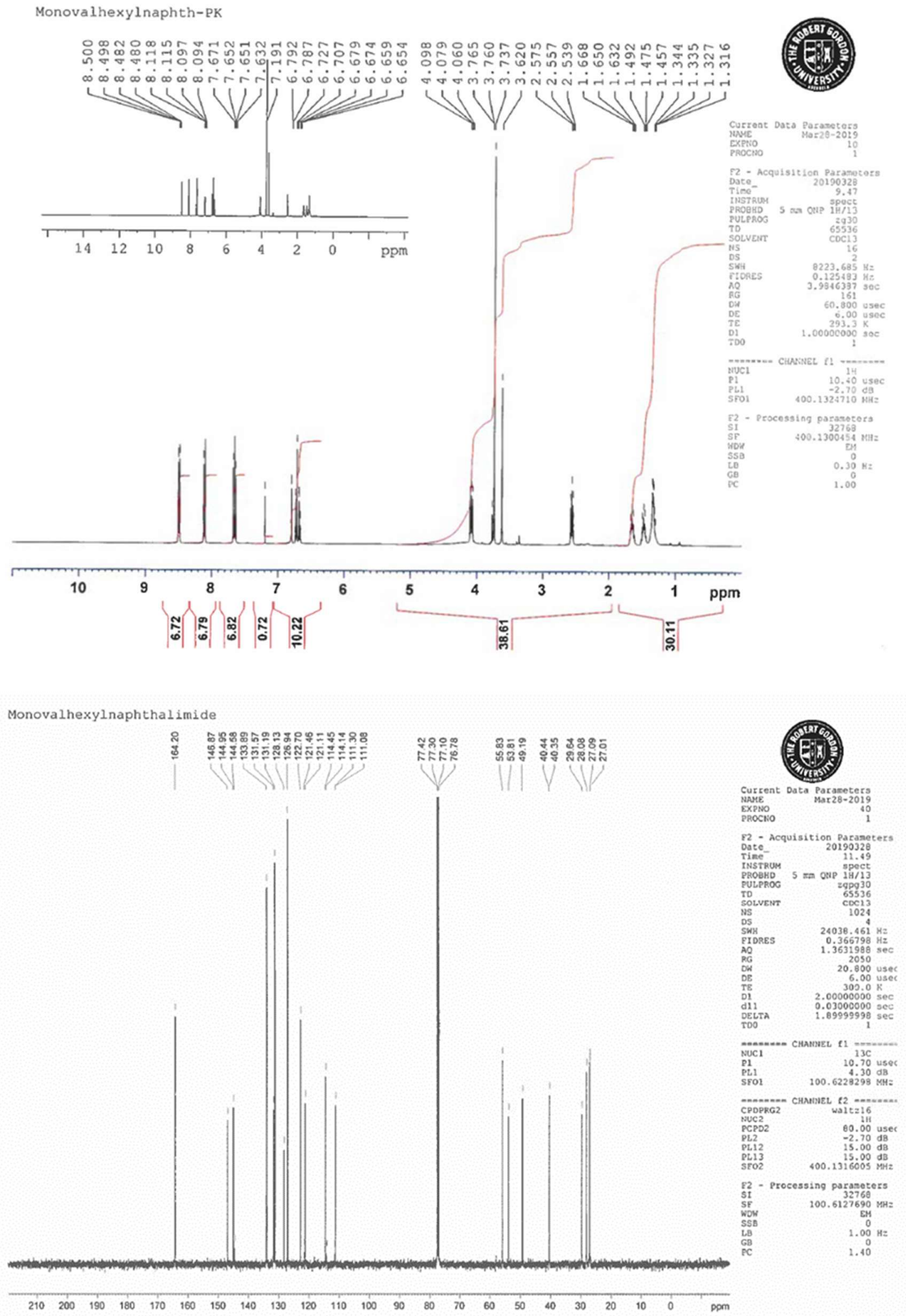


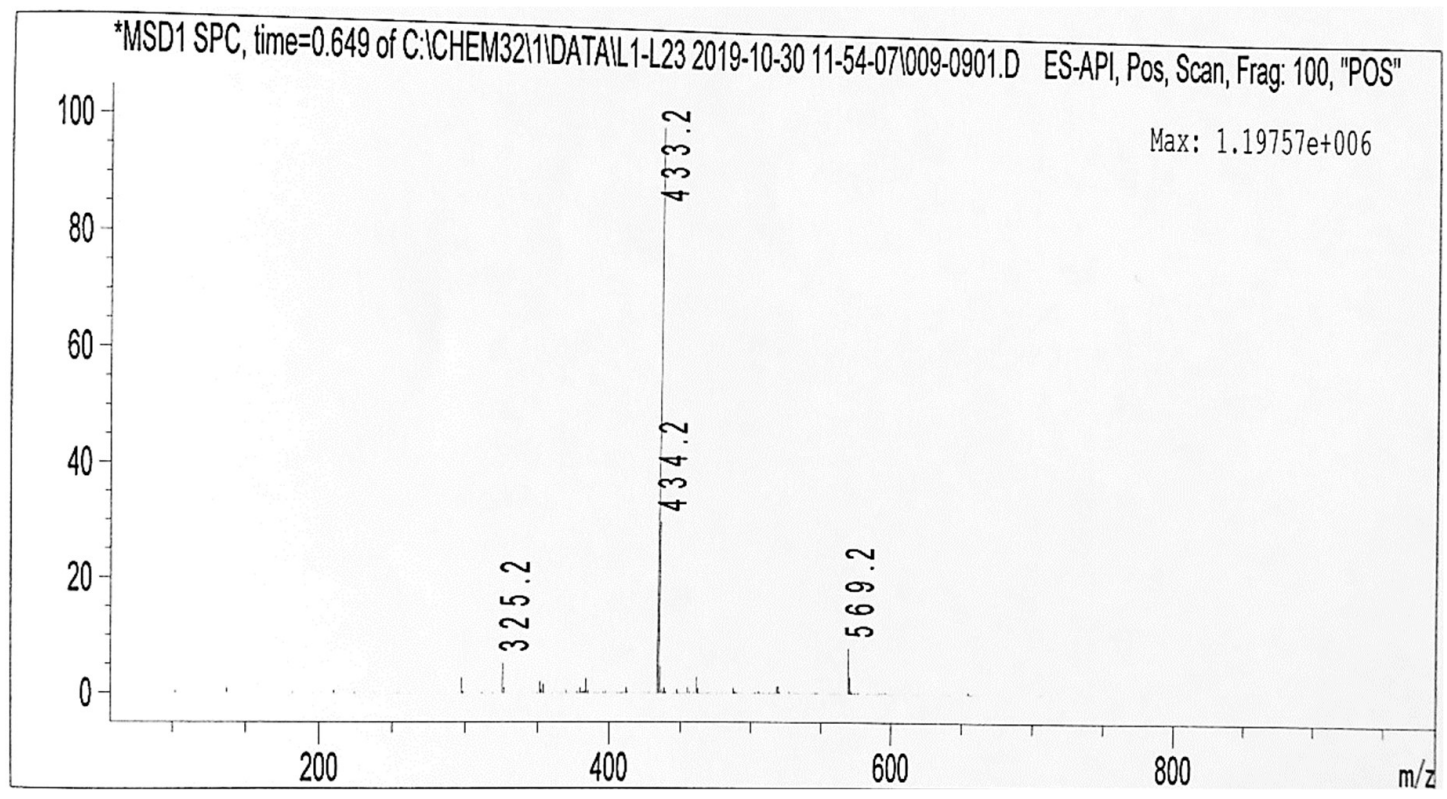



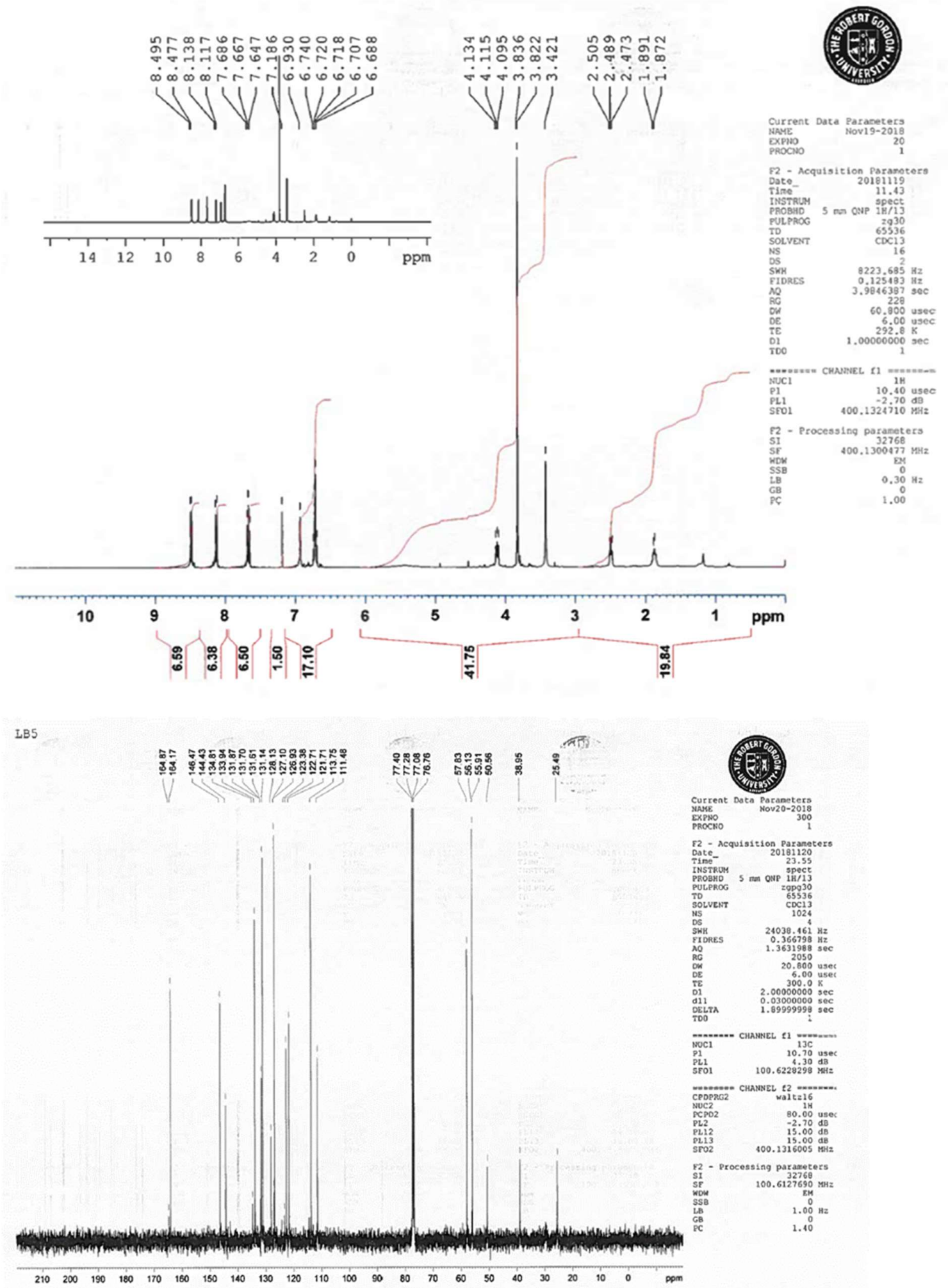


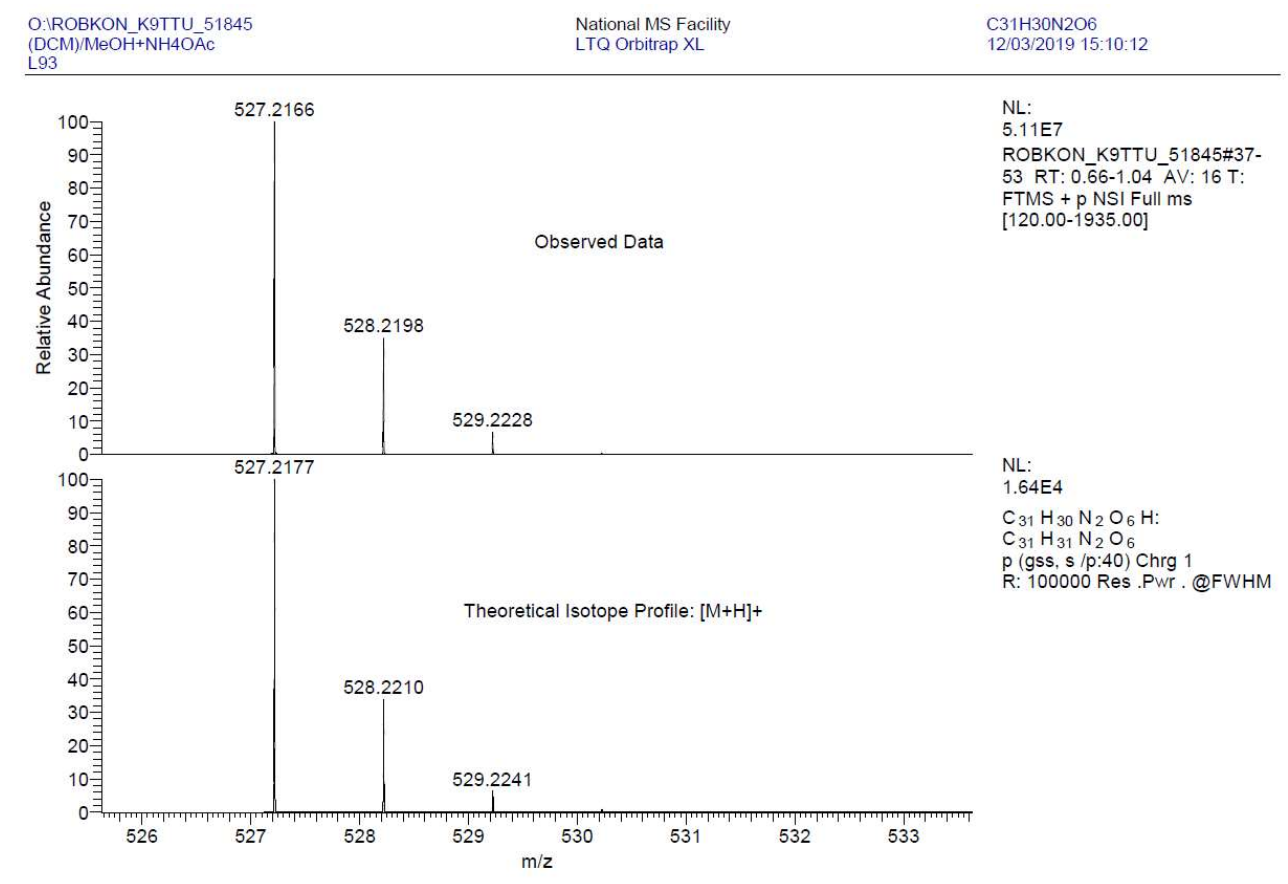




\section{Compound $\mathbf{3 a}$}
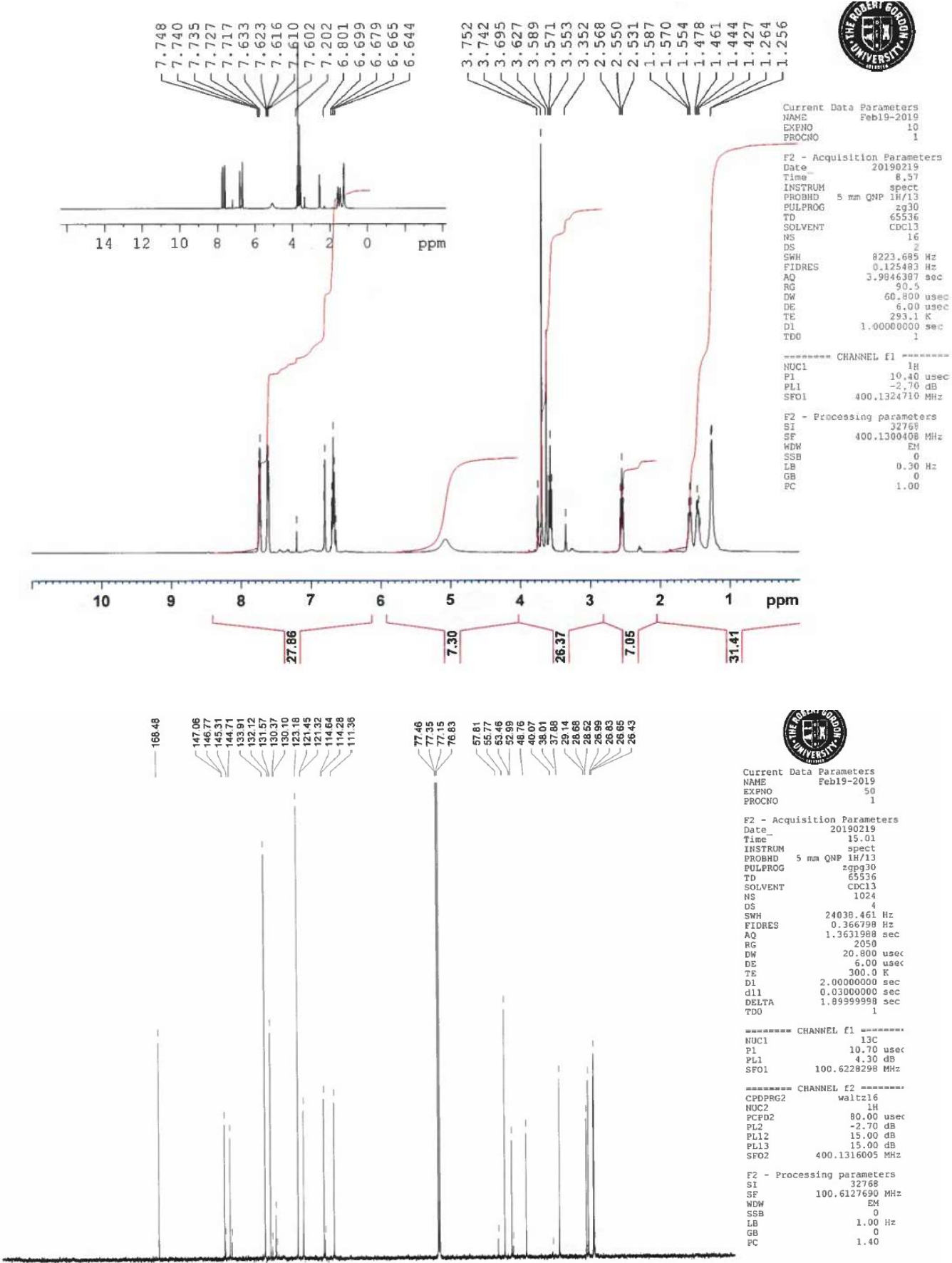

$\begin{array}{lllllllllllllllllllllllllll}210 & 200 & 190 & 180 & 170 & 160 & 150 & 140 & 130 & 120 & 110 & 100 & 90 & 80 & 70 & 60 & 50 & 40 & 30 & 20 & 10 & 0 & p p m\end{array}$ 


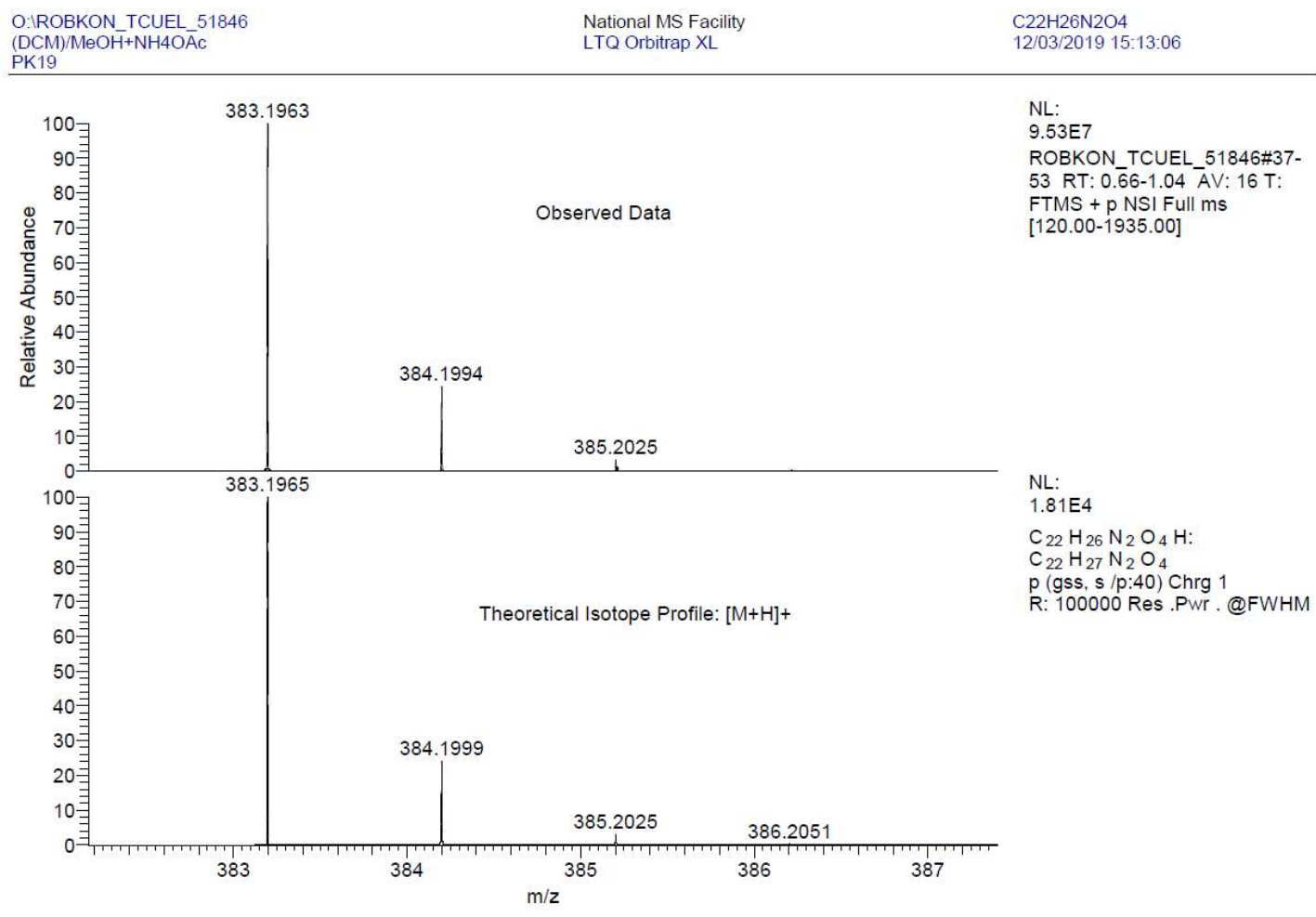




\section{Compound $\mathbf{4 a}$}

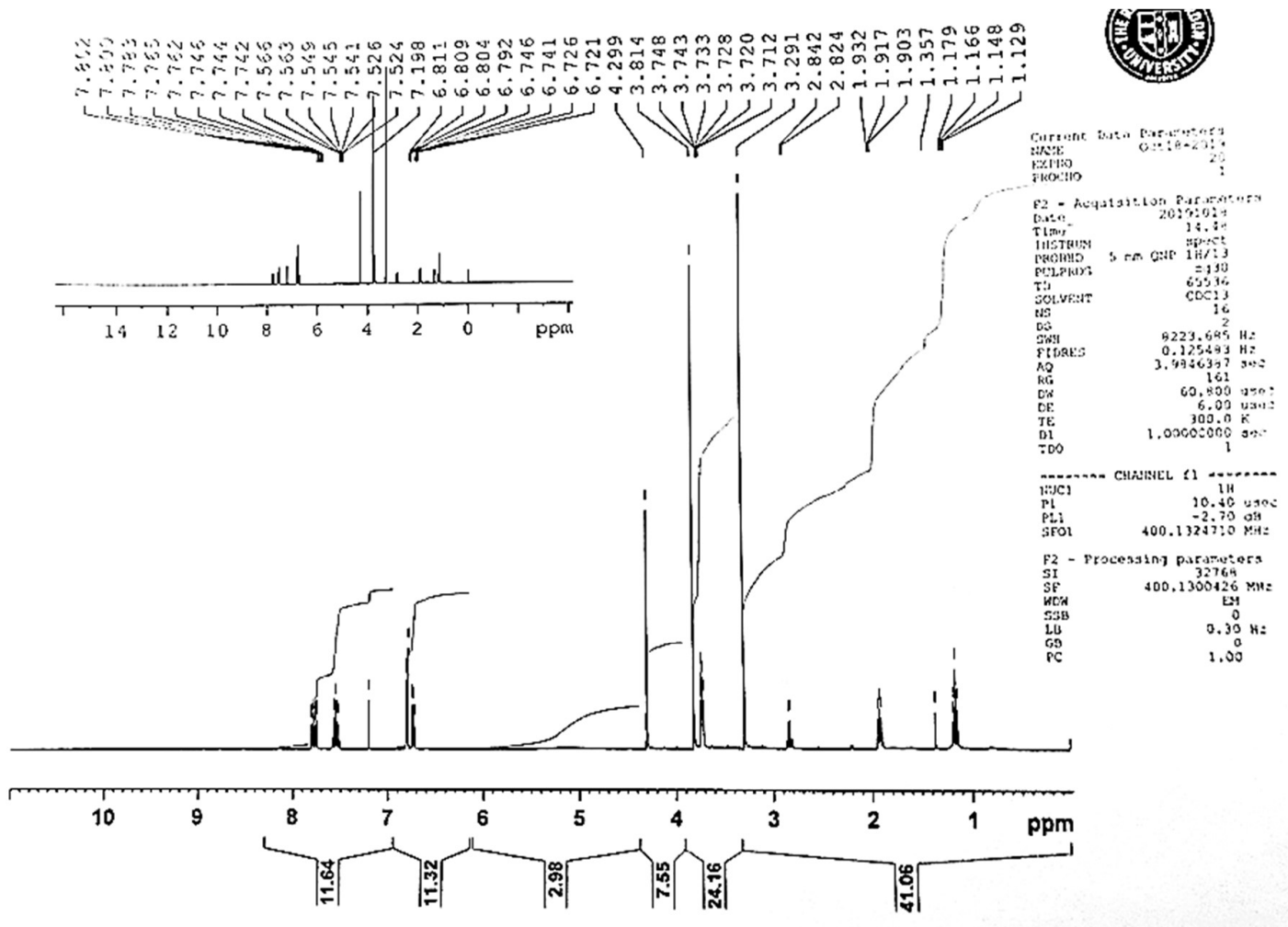

:.5xบe?3
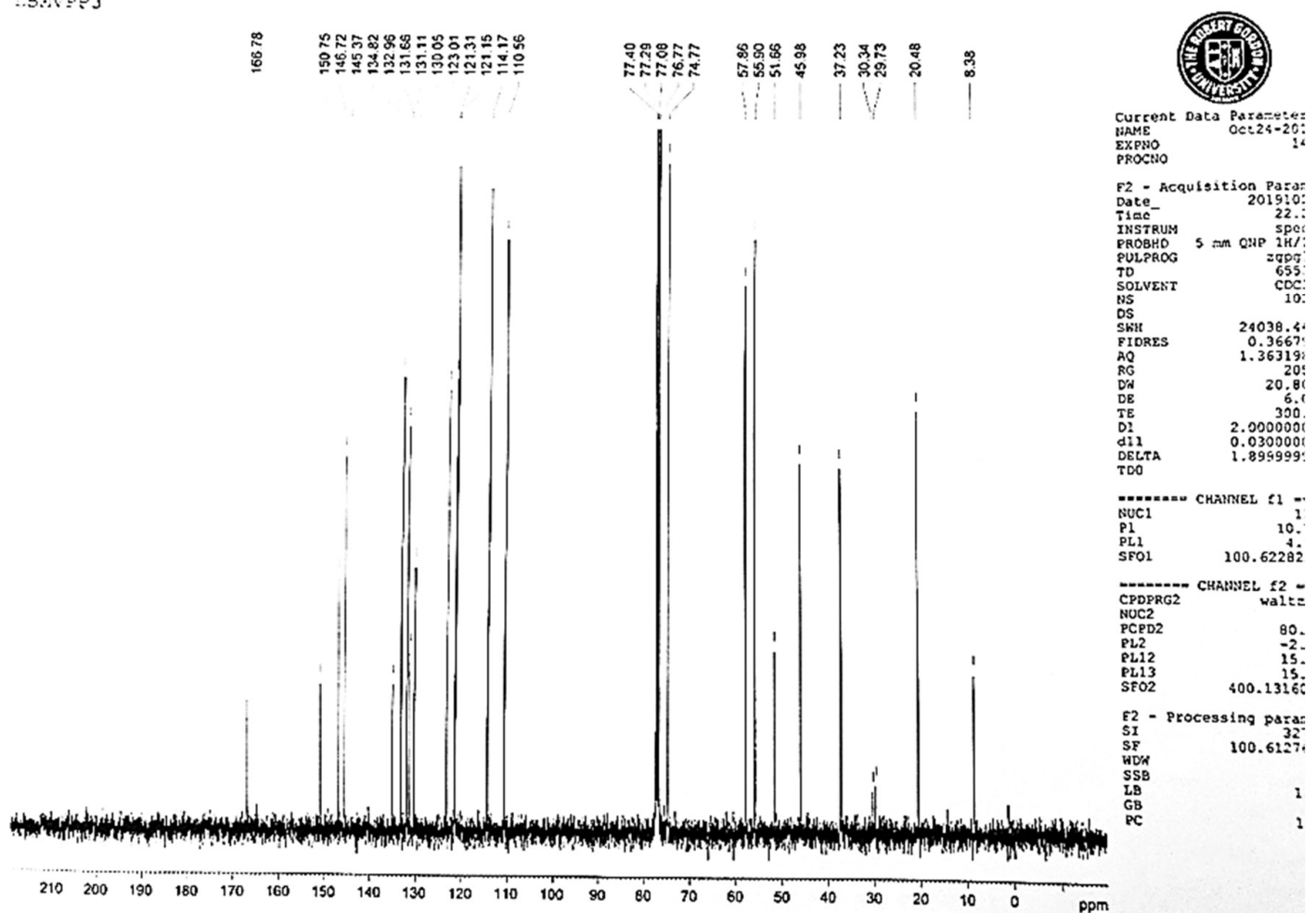


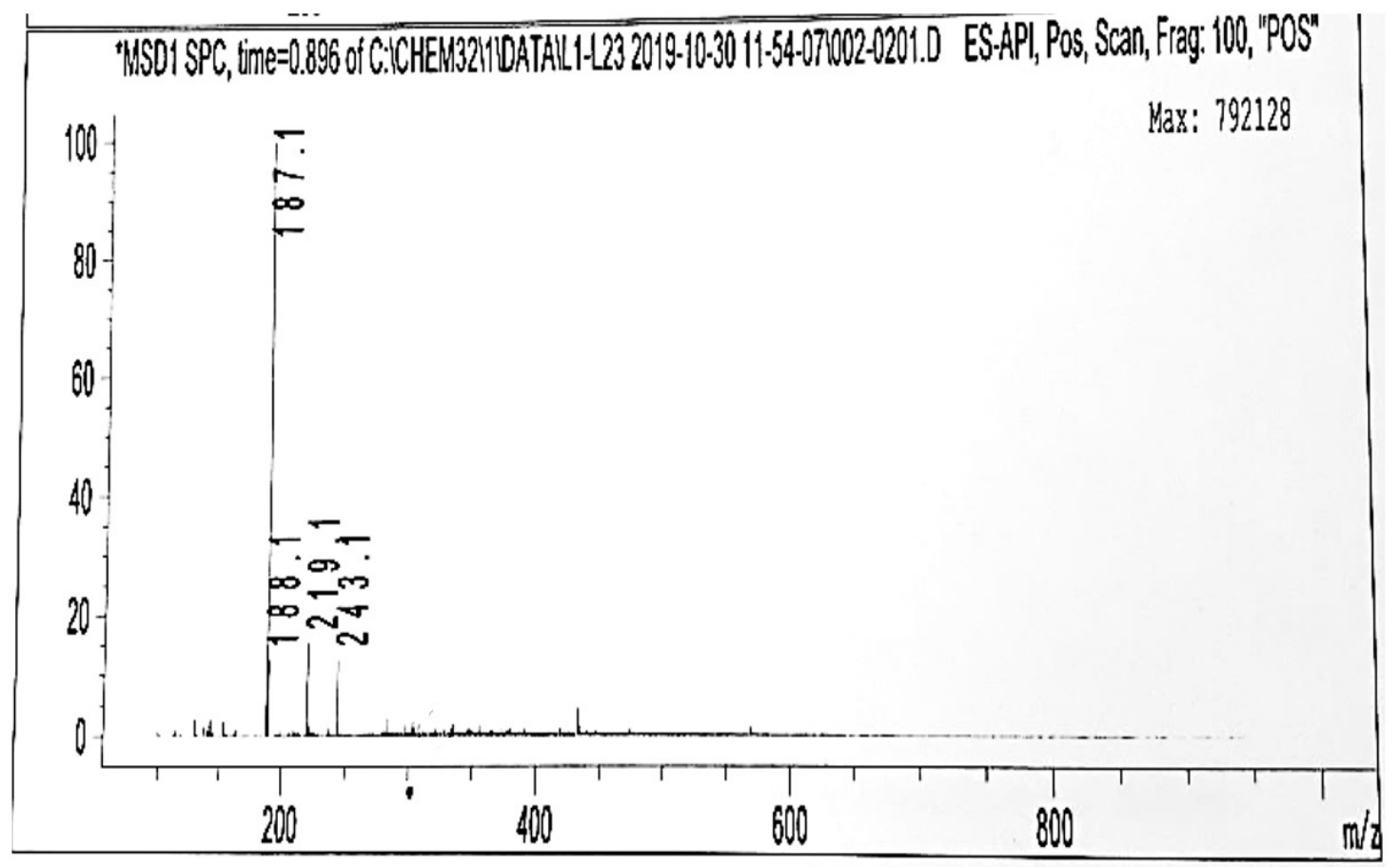


References

1. Payet B, Sing ASC, Smadja J. Assessment of antioxidant activity of cane brown sugars by ABTS and DPPH radical scavenging assays: Determination of their polyphenolic and volatile constituents. J Agric Food Chem. 2005;53:10074-10079. doi: $10.1021 /$ jf0517703

2. Firuzi O, Lacanna A, Petrucci R, Marrosu G, Saso L. Evaluation of the antioxidant activity of flavonoids by "ferric reducing antioxidant power" assay and cyclic voltammetry. Biochim Biophys Acta - Gen Subj. 2005;1721:174-184. doi: $10.1016 /$ j.bbagen.2004.11.001

3. Huang D, Ou B, Hampsch-Woodill M, Flanagan JA, Prior RL. High-throughput assay of oxygen radical absorbance capacity (ORAC) using a multichannel liquid handling system coupled with a microplate fluorescence reader in 96-well format.

J Agric Food Chem. 2002;50:4437-4444. doi:10.1021/jf0201529

4. Ellman GL, Courtney KD, Andres V, Featherstone RM. A new and rapid colorimetric determination of acetylcholinesterase activity. Biochem Pharmacol. 1961;7:88-95. doi:10.1016/0006-2952(61)90145-9

5. Trott O, Olson AJ. AutoDock Vina: Improving the Speed and Accuracy of Docking with a New Scoring Function, Efficient Optimization, and Multithreading. J Comput Chem. 2010;31:455-461. doi:10.1002/jcc.21334

6. Liu H, Wang L, Lv M, et al. AlzPlatform: An Alzheimer's disease domainspecific chemogenomics knowledgebase for polypharmacology and target identification research. J Chem Inf Model. 2014;54:1050-1060. doi:10.1021/ci500004h 